\title{
The Role of Technology Readiness in acceptances of E-Course Registration System
}

Journal of

TANMIYAT ALRAFIDAIN

\section{(TANRA)}

A scientific, quarterly, international, open access, and peer-reviewed journal

Vol. 39, No. 128

Dec., 2020

(C) University of Mosul | College of Administration and Economics, Mosul, Iraq.

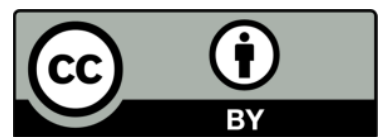

TANRA retain the copyright of published articles, which is released under a "Creative Commons Attribution License for CC-BY-4.0" enabling the unrestricted use, distribution, and reproduction of an article in any medium, provided that the original work is properly cited.

Citation: Alsumaidaie Abdullah A. K. (2020)."The Role of Technology Readiness in acceptances of E-Course Registration System. TANMIYAT AL-RAFIDAIN, 39 (128), 173195 ,

https://doi.org/10.33899/tanra.20 20.167374

P-ISSN: 1609-591X e-ISSN: 2664-276X tanmiyat.mosuljournals.com

\author{
Abdullah A. K. Alsumaidaie \\ College of Administration and Economics, The University of Mosul, Iraq. \\ Corresponding author: Abdullah A. K. Alsumaidaie, \\ abdullah abdulhak@uomosul.edu.iq
}

DOI: $10.33899 /$ tanra.2020.167374

Article History: Received: 2/7/2020; Revised: 12/8/2020; Accepted: 28/7/2020; Published: $1 / 12$ /2020.

\begin{abstract}
This study aims to identify the employees' technology readiness in the student registration units at the University of Mosul and its effect on acceptance of the new E-Course Registration System. To achieve the goals of the study, a special questionnaire was prepared based on the (TRI 2.0) with written permission from the authors, also the indicators of the technology acceptance model. The questionnaire was distributed to all employees in the registration units in the colleges of the University of Mosul, where (133) usable questionnaires were retrieved out of (146) distributed, which is equivalent to (91\%) Retrieval. study data processed and hypotheses tests were using SPSS and SmartPLS software. The study found that some dimensions of the employees' technology readiness have a significant effect on the intention to accept the E-Course Registration System. Besides, the results indicated a significant difference in the employees' technology readiness, and acceptance uses the E-Course Registration System due to the variables as educational level, service years, computer, and E-Course Registration System training, while gender and age variables do not affect.
\end{abstract}

\section{Keywords}

Technology Readiness Index, Technology Acceptance Model, E-Course Registration System. 


\section{ورقة بحثية \\ دور الجاهزية التكنولوجية في قبول نظام المقررات الإكتروني}

\author{
عبدالله عبدالحق خميس الصميدعي \\ جامعة الموصل، كلية الإدارة والاقتصاد، قسم نظم المعلومات الإدارية
}

المؤلف المراسل: عبدالله عبدالحق خميس الصميدعي،

abdullah_abdulhak@uomosul.edu.iq

DOI: 10.33899/tanra.2020.167374

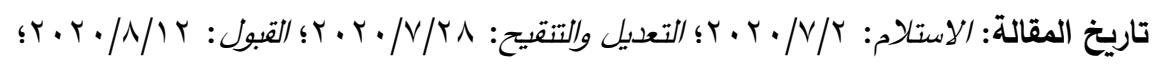

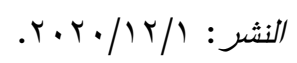

المستخلص

جاءت هذه الدراسة للتعرف على الجاهزية التكنولوجية للعاملين في شعبة التسجيل في جامعة الموصل وأثرها

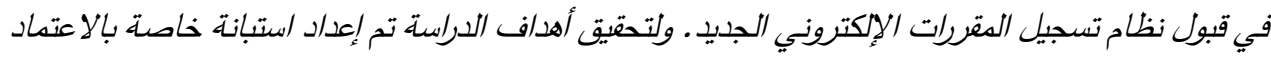

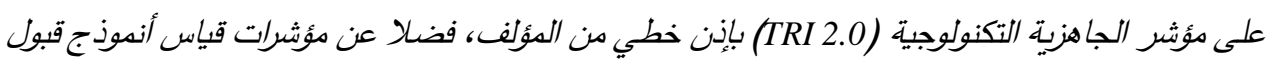

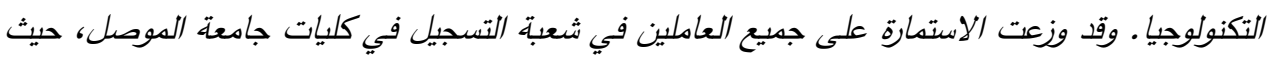

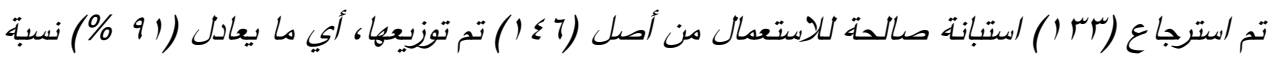

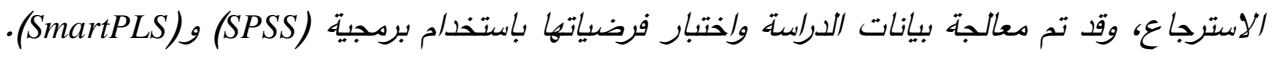

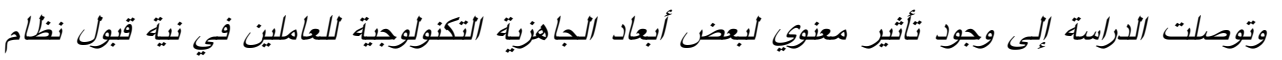

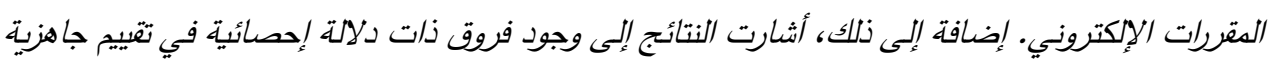

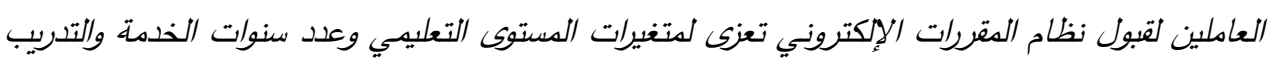

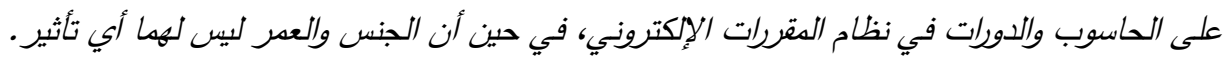

الكلمات المفتاحية مؤشر الجاهزية التكنولوجية، أنموذج القبول التكنولوجي، نظام تسجيل المقررات الإكتروني.

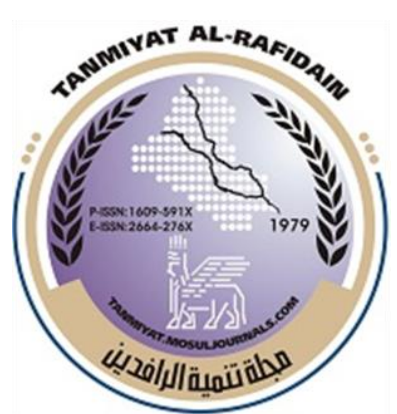

\section{هبلة}

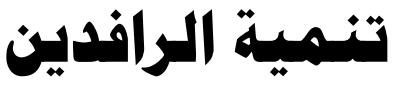

(TANRA) دولية، مفتوحة الوصول، محكمة.

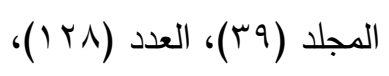

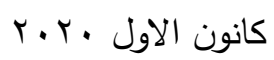

ج جامعة الموصل | (c) كلية الإدارة والاقتصاد، الموصل، العراق.

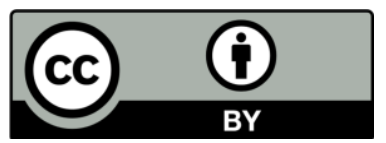

تحتفظ (TANRA) بحقوق الطبع والنشر للمقالات المنشورة، والتي يتم إصدارها بموجب ترخيص لئن ل(Creative Commons Attribution) (CC-BY-4.0) والاستنساخ غير المقيد وتوزيع للمقالة في أي وسيط الأني نقل، بشرط اقتباس العمل الأصلي بشكل صحيح.

الاقتباس: الصميدعي، عبداله عبدالحق

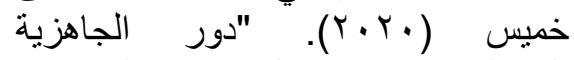
التكنولوجية في قبول نبول نظام المقررات

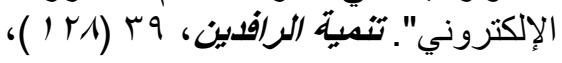
6) 190-1Vr

https://doi.org/10.33899/tanra.20 20.167374

P-ISSN: 1609-591X

e-ISSN: 2664-276X

tanmiyat.mosuljournals.com 
تســـعى الجامعات العراقية إلى مواكبة الجامعات العالمية وإحداث قفزة نوعية في تعزيز الرصــــانة

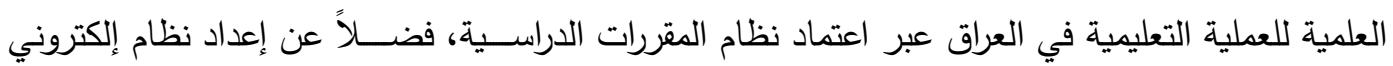
لآلية عمل نظام المقررات وهذا يتطلب توفير ملاك إداري مطلع ومؤهل للعمل على هذا النظام، وعلى الرغم من أهمية استخدام نظام المقررات الإكتروني لما يحدثه من تغيير جذري في كيفية أداء العمل بالنسبة للعاملين الا انه قد يخلق نوعاً من مقاومة التغيير لدى العاملين الذين قد يجتتبون استخدام مثل هذه النظم إذا ما شعروا

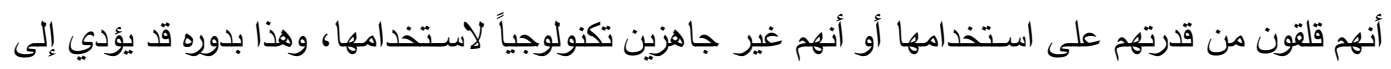

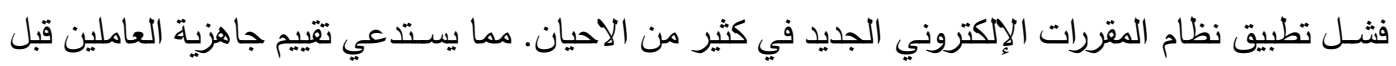

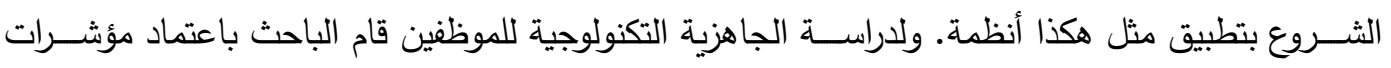

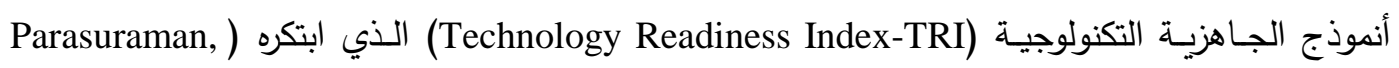

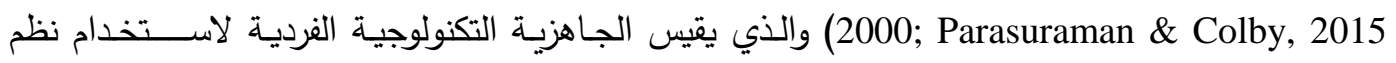

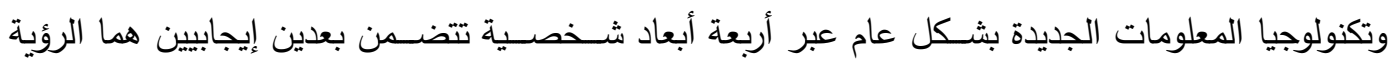

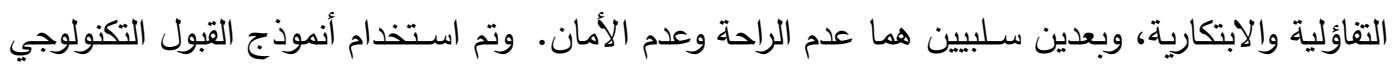
Davis, 1985; Venkatesh and Davis, ) الذني ابتكره (Technology Acceptance Model-TAM)

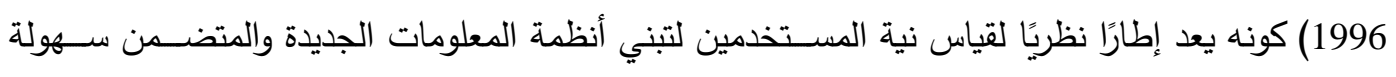
الاستخدام المتوقعة، والفائدة المتوقعة، والنية السلوكية لاستخدام النظام. منهجية الاراسة أولاً: مشكلة الدراسة قد يواجه تطبيق نظام المقررات إلكتروني في الجامعات العراقية الفثــلـ عبر عدم رغبة العاملين في

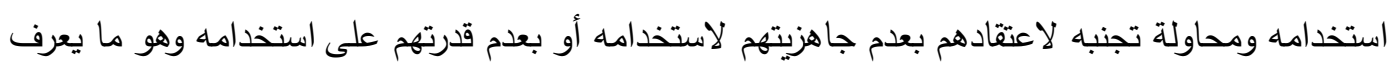

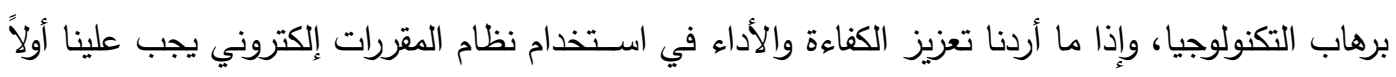
تحسين رغبة المستخدمين وتغيير قناعاتهم، ولكن قبل تحسين رغبة المستخدمين يجب أن نفهم اتجاهاتهم

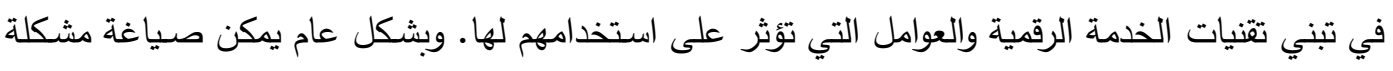

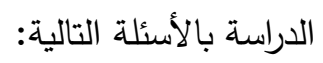

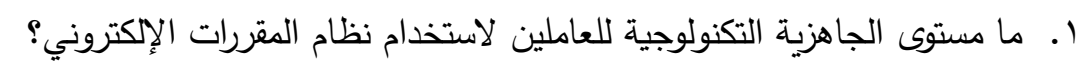

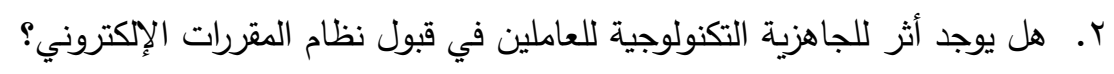

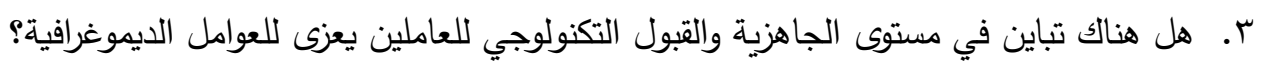
ثانياً: أهداف الدراسة تهدف الدراســة إلى معرفة مسـتوى الجاهزية التكنولوجية للعاملين وأثرها في نية قبول نظام المقررات

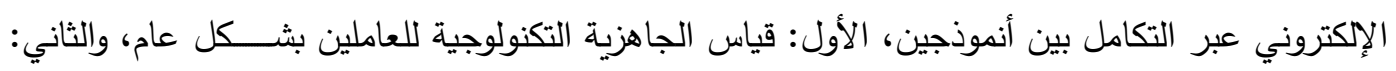


أنموذج قبول التكنولوجيا لمعرفة نية العاملين لقبول النظام الإكتروني، ويمكن تلخيص أهداف الدراســــة بما الآتية: ا. التعرف على مدى إدراك العاملين للسهولة والفائدة المتوقعة لاستخدام نظام المقررات الإكتروني. r. التعرف على أثر الجاهزية التكنولوجية للعاملين في النية لقبول نظام المقررات الإكتروني. r. تثخيص التباين في مستوى الجاهزية والقبول التكنولوجي للعاملين وفقاً للعوامل الديموغرافية.

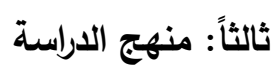

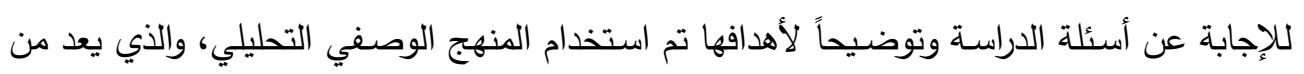

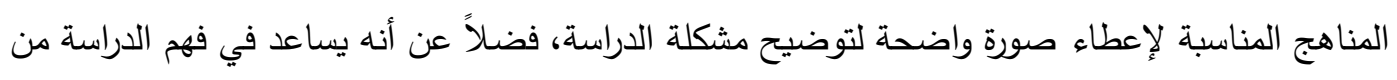

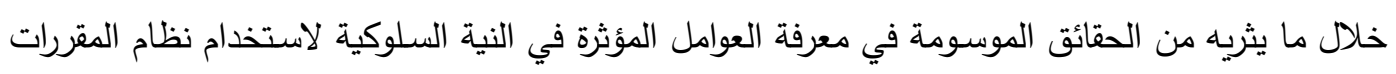
الإككتروني عبر قياس الجاهزية التكنولوجية للمستخدمين ومعرفة مدى تأثيرها في سـهولة الاستخدام والفائدة المتوقعة لاستخدام نظام المقررات من قبل العاملين في شعب التسجيل وشؤون الطلبة في جامعة الموصل. رابعاً: أداة الدراسة تم إعداد أداة الدراسة وتهيئتها ليمثل الجزء الأول المعلومات الديموغرافية لأفراد عينة الدراسة (الجنس،

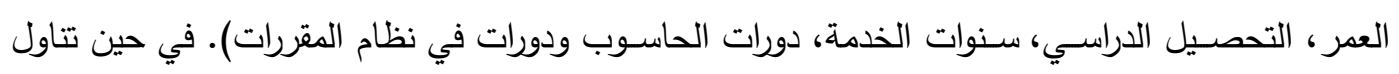

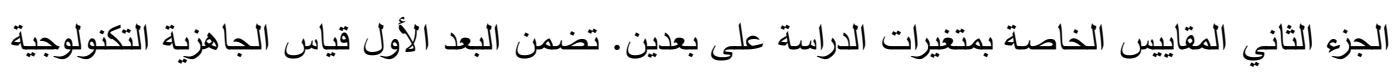

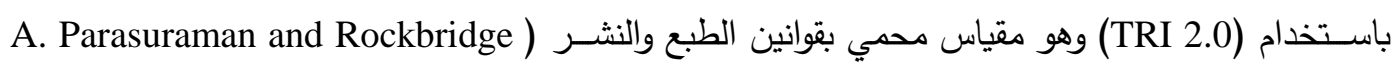
Parasuraman and ) ويتطلب اسـتخدامه الحصـول على ترخيص وأذن خطي منهما (Associates, Inc.

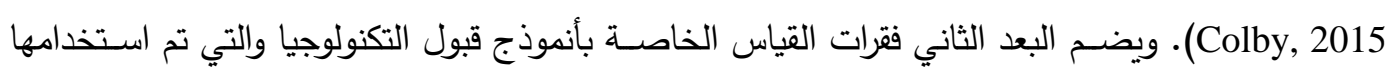
بالاسـتناد إلى دراسـة كل من (Venkatesh and Davis, 1996; Thanoon, 2016). وتم تصــميم فقرات الاستبيان لقياس متغيرات الدراسة بناءً على إجابات متدرجة بحسب أنموذج ليكرت الخماسي. خامساً: الأساليب الإحصائية

إن أسـلوب التحليل الملائم يسـتــد على نوع البيانات المطلوب تحليلها بثـكل رئيس، وتم اسـتخدام الحزمة الإحصائية (SPSS) ونمذجة المعادلات الهيكلية القائمة على المربعات الصغرى الجزيئية، وتم اعتماد

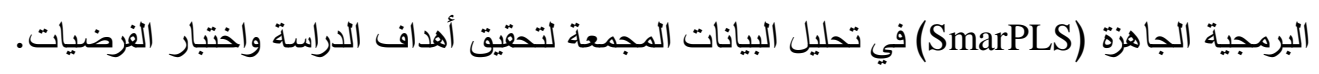
وفي ضوء طبيعة متغيرات الدراسة وأساليب القياس وأغراض التحليل تم استخدام الأساليب الآتية:

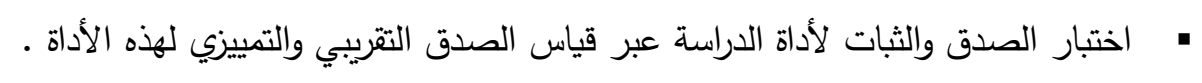

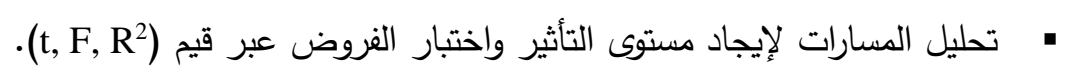
• اختبار tوتحليل التباين الأحادي لإيجاد الفروق المعنوية بين العينتين. 
سادساً: حدود الدراسة

تمثلت الحدود المكانية للبحث بثـعب التسـجيل والثـؤون الطلابية في جامعة الموصـل كونها الجهة

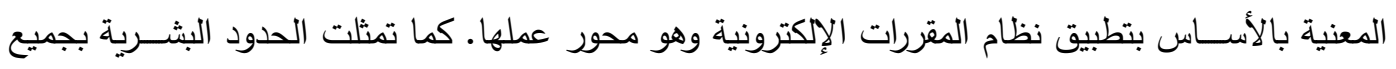
العاملين في شعب التسجيل والثؤون الطلابية في جامعة الموصل كونهم الفئة الرئيسة المستهدفة من النظام

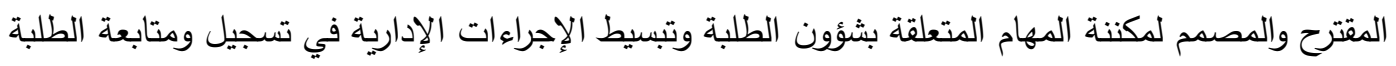

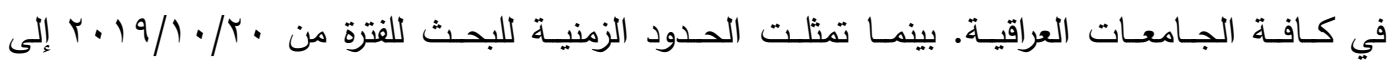
$r \cdot r \cdot / r / l$.

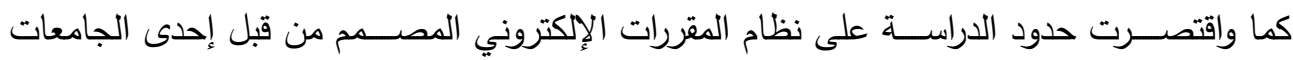

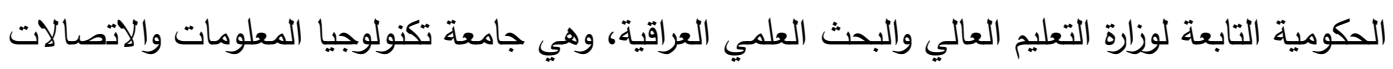

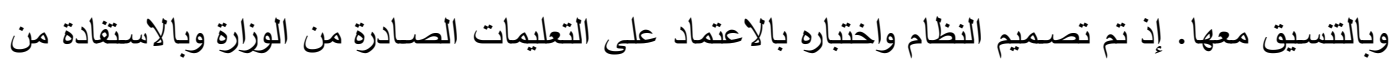

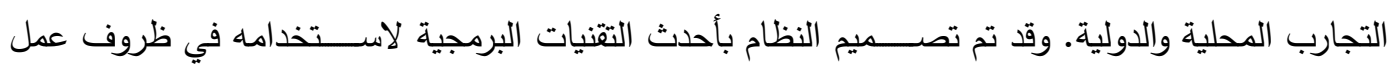

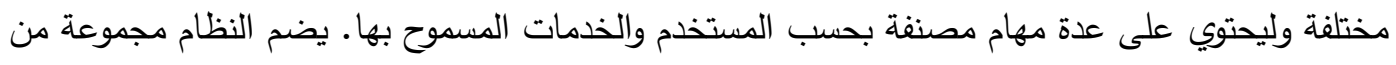

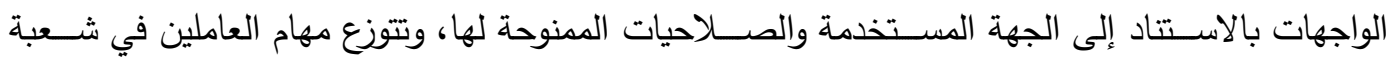

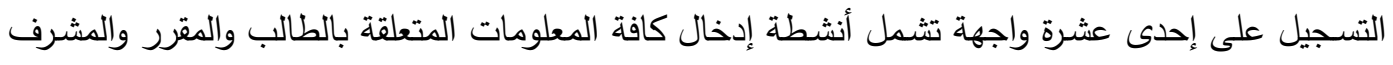

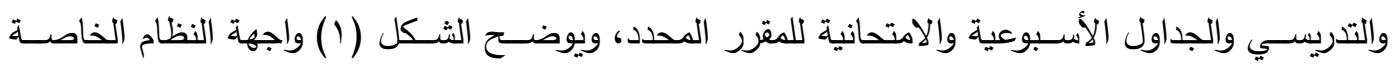
بإضافة بيانات الطالب من قبل العاملين في شعبة التسجيل في الكلية (ECS, 2019). الجانب النظري

أولاً: الجاهزيـة التكنولوجية (TR)

تم التطرق إلى مفهوم الجـاهزيـة التكنولوجيـة لأول مرة في مجال التســـويق لمعرفة طريقة تفاعل

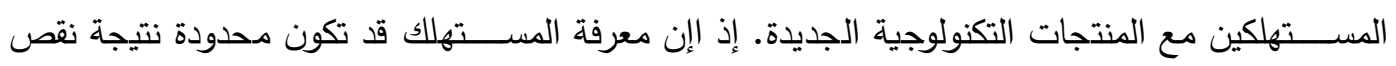

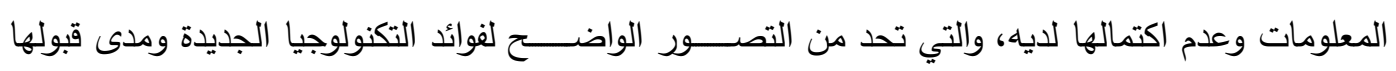

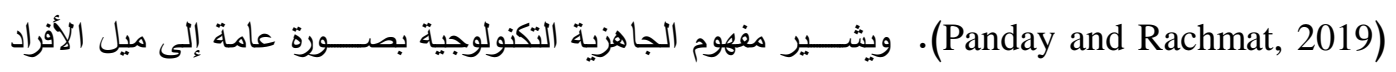

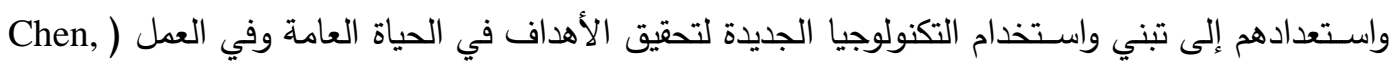

.(Liu, \& Lin, 2013 


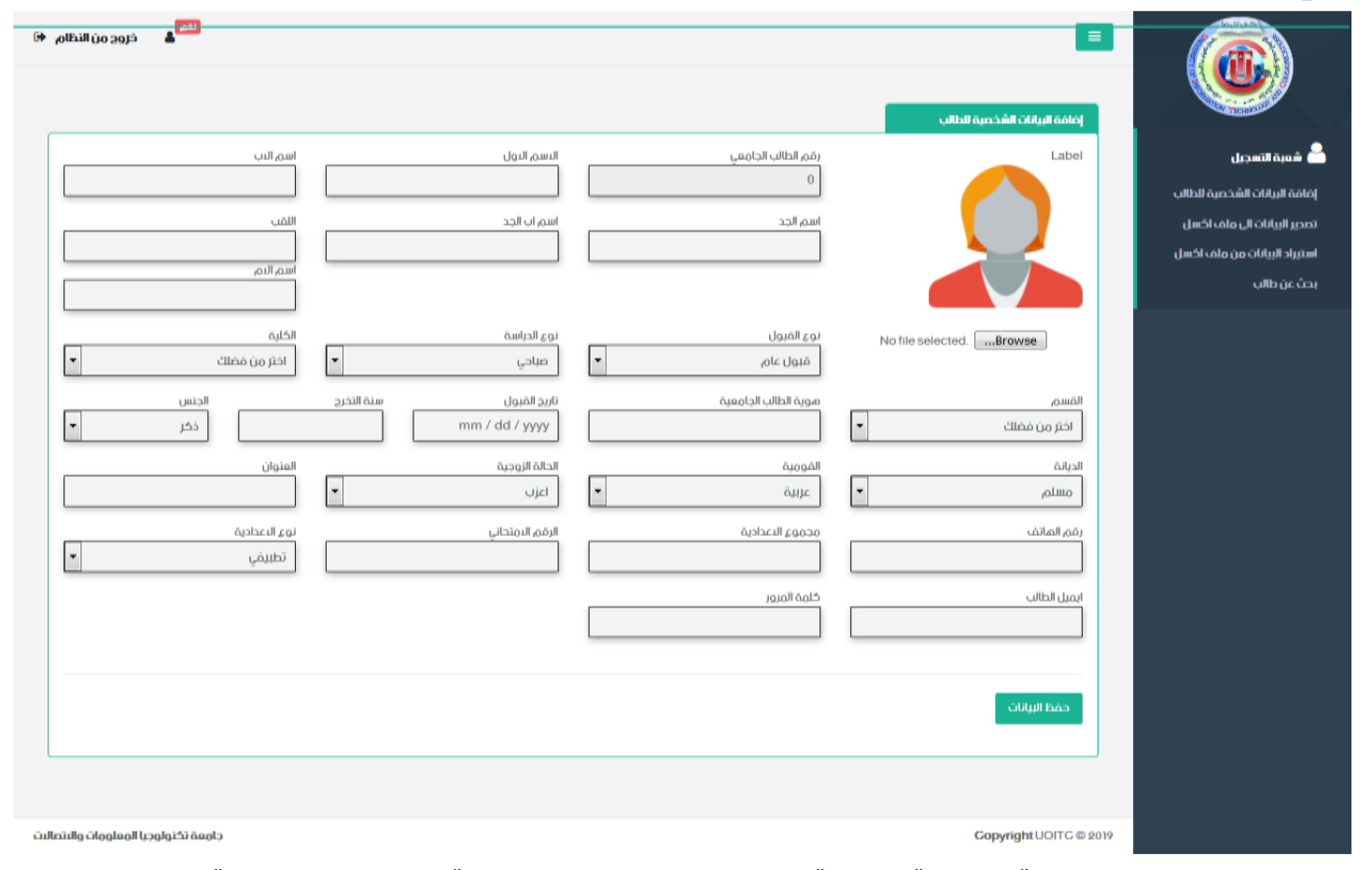

الثكل (1) الواجهة الخاصة بإضافة بيانات الطالب من قبل شعبة التسجيل في الكلية

Source: ECS- Electronic Course System Documentation Manual. (2019). Ministry of Higher Education and Scientific Research, University of Information and Communications Technology, first edition.

وقد قام البروفسـور Parasuraman (2000) بوضـــع مؤشــرات عدة كمقياس للجاهزية التكنولوجية

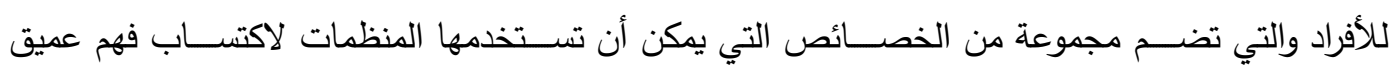

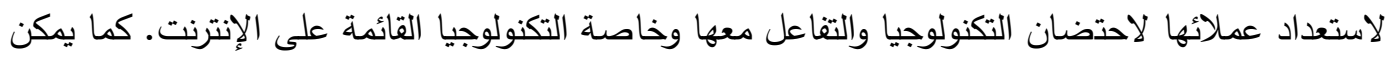

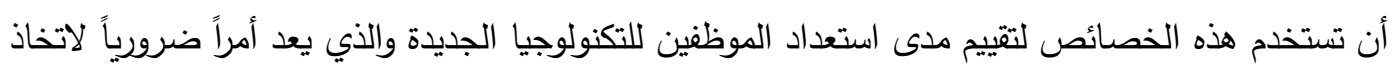

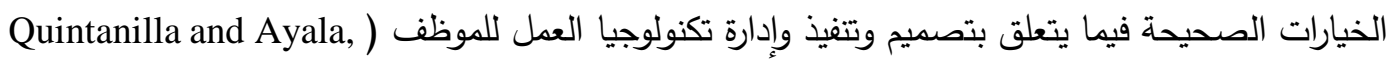

وقد أكد Bessadok, Lassaad, Hatem and Almotairi (2018) أن مؤشر الجاهزية التكنولوجية

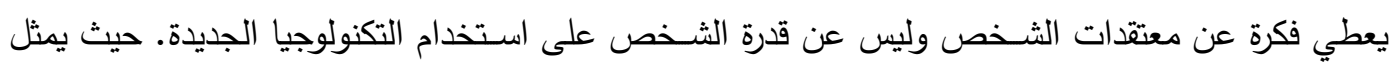
مؤشـر الجاهزية التكنولوجية مجموعة من المحفزات العقلية والمثبطات التي تحدد بثــكل جماعي اسـتـعداد الفرد لاسـتخدام التقنيات الجديدة (Pham, Nguyen, Huy, \& Luse, 2018). وتتمثل هذه المكونات بأربعة أبعاد مختلفة مثل (Demirci and Ersoy, 2008): ا. التفاؤل: هي النظرة بإيجابية للتكنولوجيا الحديثة والاعتقاد بأنها توفر للأفراد المزيد من التحكم والمرونة

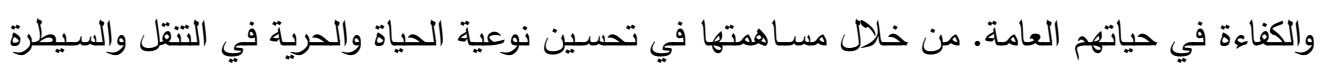
بشكل أفضل على الحياة اليومية. 
r. الابتكار : هو ميل الفرد إلى أن يكون سباقاً في استخدام تكنولوجيا المعلومات الحديثة ورائداً بين أقرانه. من خلال الاســراع في الحصــول على تكنولوجيا المعلومات الحديثة واســتخدامها قبل الآخرين ودون مســاعدة من أحد مع متابعة أحدث التطورات التكنولوجية وتقديم المســاعدة والمشـورة للآخرين بثــأن تكنولوجيا المعلومات الحديثة. r. عدم الراحة: هو شعور الفرد بالإرهاق وعدم السيطرة على تكنولوجيا المعلومات الجديدة لاعتقاده بأنها

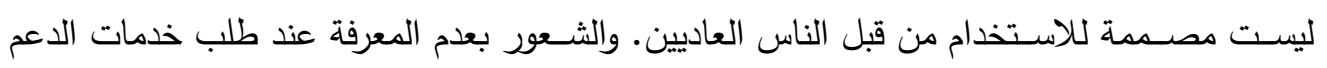
الفني لاستخدام التكنولوجيا الحديثة مقارنة بمقدم الخدمة.

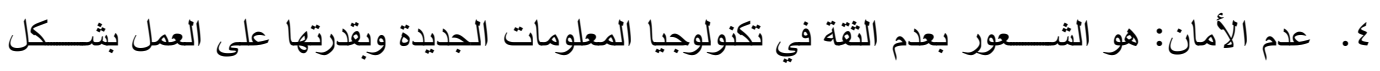

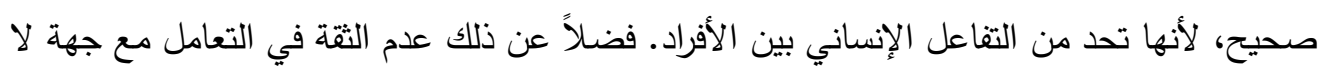

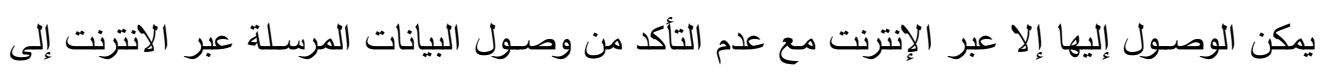
الجهة التي يريدها الفرد. إذ يمثل التفاؤل والإبتكار المحركين أو المحفزين لاســـتخدام التكنولوجيا، في حين إن انعدام الراحة

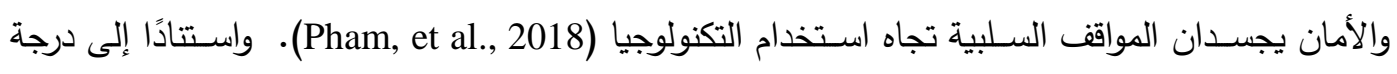

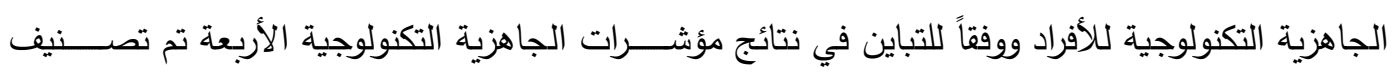

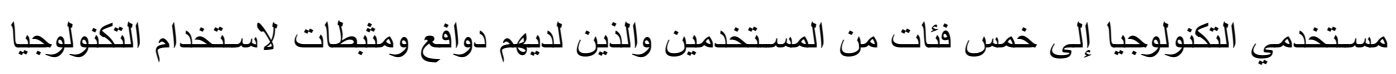
الجديدة تختلف من فئة لأخرى وهذه الفئات هي (Lai, 2008).

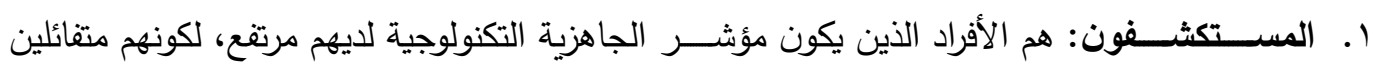

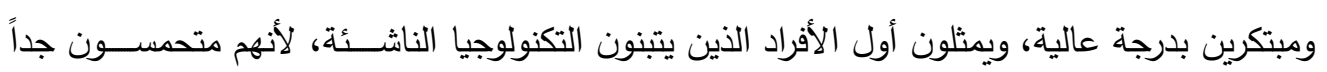

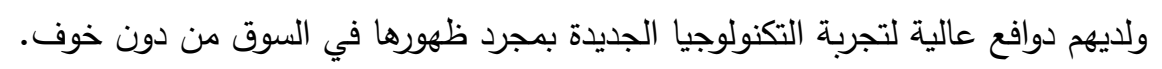

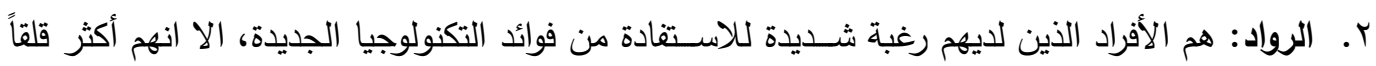
للمخاطر التي قد تحدث نتيجة استخدام هذه التكنولوجيا. ويمثلون نسبيًا أوائل الأفراد الراغبين باستخدام

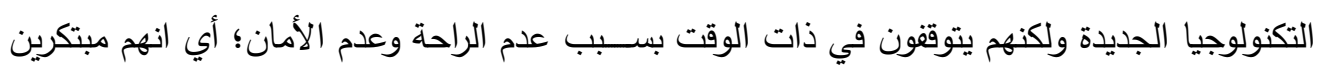

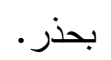

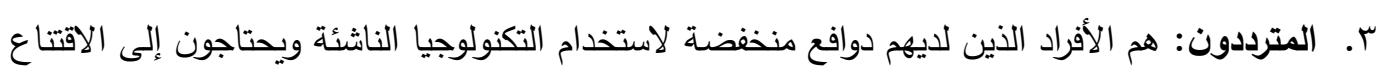

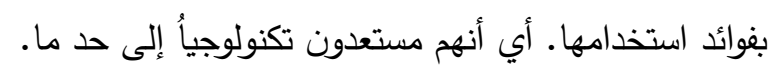

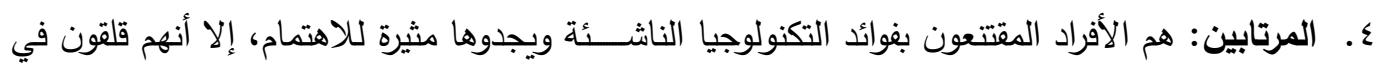
الوقت نفسه من مخاطر وحواجز تبني التكنولوجيا الناشئة ويشعرون بعدم الأمان.

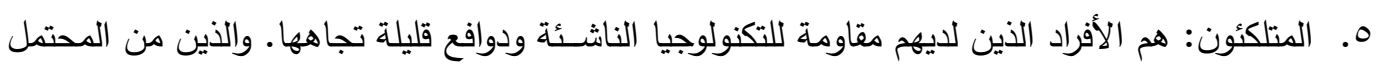

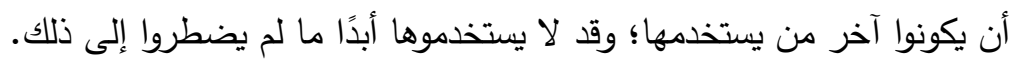


ويوضـــح الجدول (1) تقســـيم فئات الأفراد العاملين في المنظمة وعلى وفق مســـتى الجاهزية

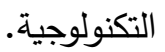

الجدول (1): فئات العاملين وفق مؤشر الجاهزبة التكنولوجية

\begin{tabular}{|c|c|c|c|c|c|}
\hline عدم الامان & عدم الراحة & الابتكار & التفاؤل & الفئة المؤشرة & ت \\
\hline منخفض & منخفض & مرتقع & مرتفع & المستكثفون & 1 \\
\hline مرتفع & مرتفع & مرتقع & مرتفع & الرواد ل & r \\
\hline منخفض & منخفض & منخفض & منخفض & المترددون & $r$ \\
\hline مرتفع & مرتفع & منخفض & مرتفع & المرتابون & $\varepsilon$ \\
\hline مرتفع & مرتفع & منخفض & منخفض & المتلكئون & 0 \\
\hline
\end{tabular}

Source: Bessadok, Adel \& Lassaad, Smirani \& Hatem, Khaled \& Almotairi, A. (2018). Internet of Things Users Classification According to Their Technology Readiness Index. 37-44.

لقد تم استخدم مقياس أو مؤشر الجاهزية التكنولوجية TRI 1.0، والذي يضم بس عنصراً موزعاً على

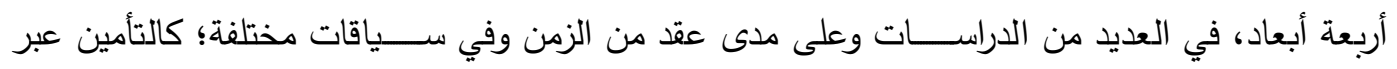

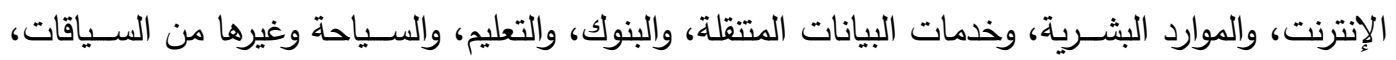

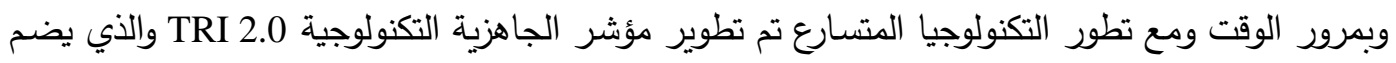

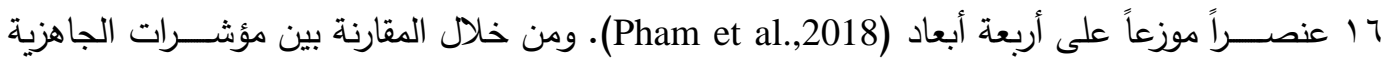

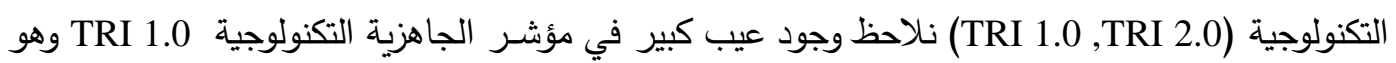
طول المقياس والذي يضم بr مؤشراً، في حين يتمتع مؤشر الجاهزية التكنولوجية المحدث TRI 2.0 TRI بقابلية

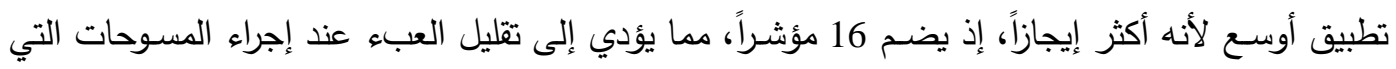

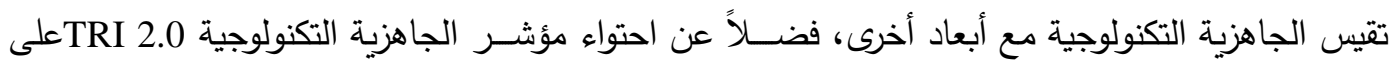

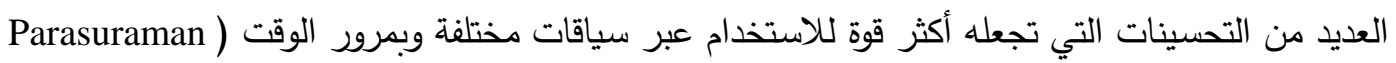
(and Colby, 2015 . وسيتم اعتماد مؤشر الجاهزية التكنولوجية TRI 2.0 في الدراسة الحالية. ثانياً: أنموذج قبول التكنولوجيا (TAM) يعد أنموذج قبول التكنولوجيا (TAM) من أهم النماذج والأوسـع انتثـاراً في دراسـات النية السـلوكية الفردية واســـتخدام التكنولوجيا الجديدة. وتم تطوير الأنموذج في البداية من نظرية الفعل العقلاني (TRA)

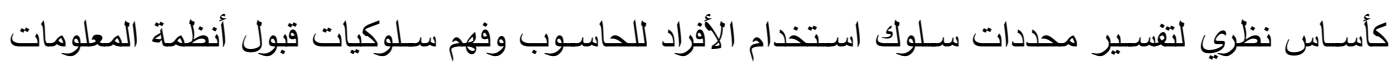
(Muniasamy, Eljailani, \& Anandhavalli, 2014) ( حيـث طور Davis (1985) أنموذج قبول التكنولوجيا (Technology Acceptance Model -TAM) ليبين أن الاســـتخدام الفعلي للنظسام يتحدد بالموقف تجاه الاســخدام والذي يتحدد بدوره بمعتقدين أسـاسـيين هما الفائدة المتوقعة وســهولة الاســخدام 
Davis, Bagozzi and المتوقعة، فضـلاً عن تأثير سـهولة الاستخدام المتوقعة في الفائدة المتوقعة. وقد قام Warshaw

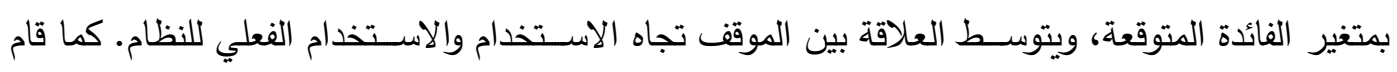
Venkatesh and Davis

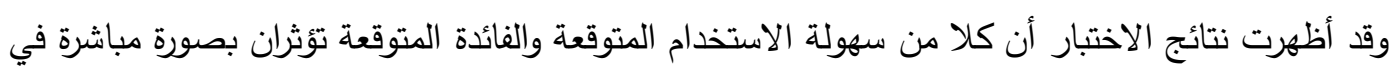

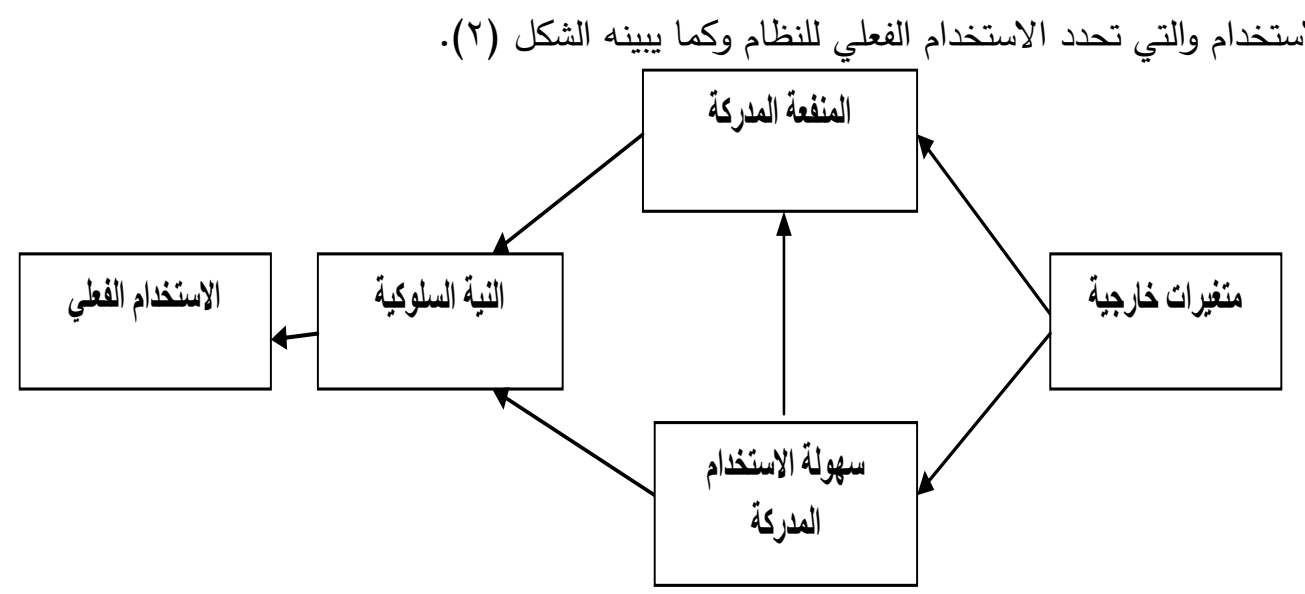

الثكل (ץ): أنموذج قبول التكنولوجيا المعدل

Source: Venkatesh, V. \& Davis, F. (1996). A Model of the Antecedents of Perceived Ease of Use: Development and Test. Decision Sciences. 27, 451-481.

كما يعد أنموذج TAM من أشـهر النماذج المستخدمة في قياس القبول للتكنلوجيا الجديدة عبر قياس

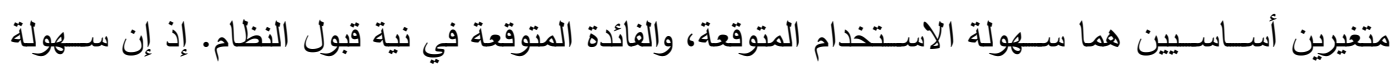
الاسـتخدام المتوقعة والفائدة المتوقعة تمثثلان عوامل اسـاسـية في قياس النية المسـتقبلية لقبول التكنولوجيا الجديدة، وهما مرتبطان بسلوكيات الأفراد لاستخدام التكنولوجيا (Legris, Ingham, \& Collerette, 2003).

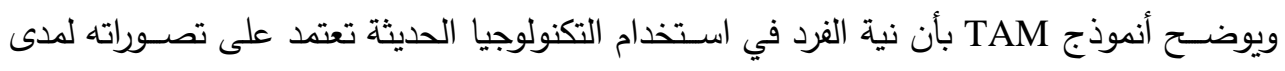

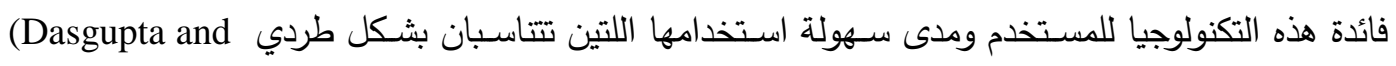
(Perceived Ease of Use - PEU) وعرف Gavis (1989) سـولة الاستخدام المتوقعة (Davis 2010) بأنها الدرجة التي يعتقد بها الفرد أن استخدام نظام معين سيكون خاليًا من الجهد البدني والعقلي. كما عرف

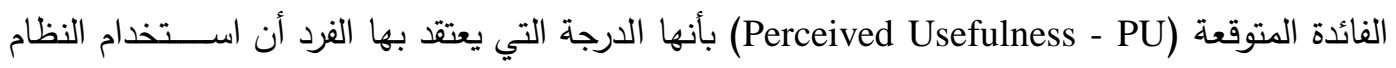

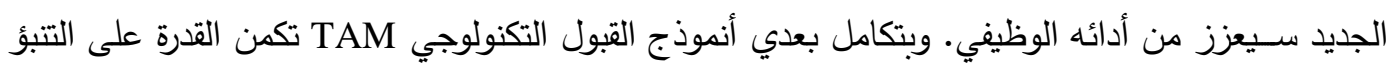
بنية الفرد لاستخدام النظام التكنولوجي الجديد، إذ كلاهما (PEU) و (PU) يؤثران على نية الفرد في استخدام النظام الجديد مستقبلاً. 


\section{الإطار التحليلي للاراسة}

أولاً: أنموذج وفرضيات الدراسة

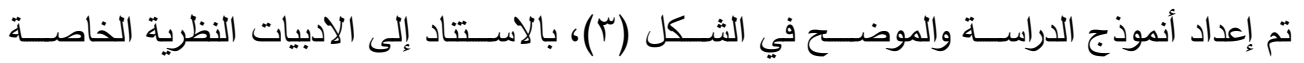

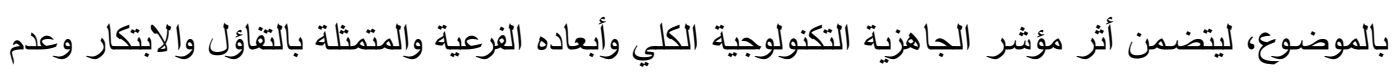
الراحة وعدم الأمان كمتغيرات كامنة تقسيرية توثر في مدى إدراك العاملين لسـهولة اسـتخدام النظام والفائدة

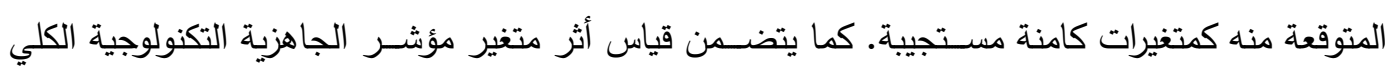

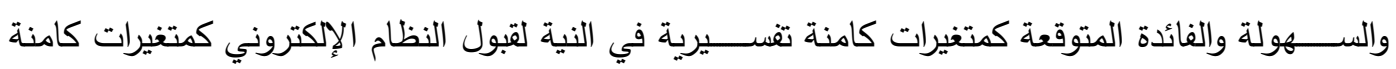
مسـتجيبة. فضـلاً عن قياس أثر متغير السـهولة المتوقعة كمتغير كامن تفسـيري في متغير الفائدة المتوقعة فئنة

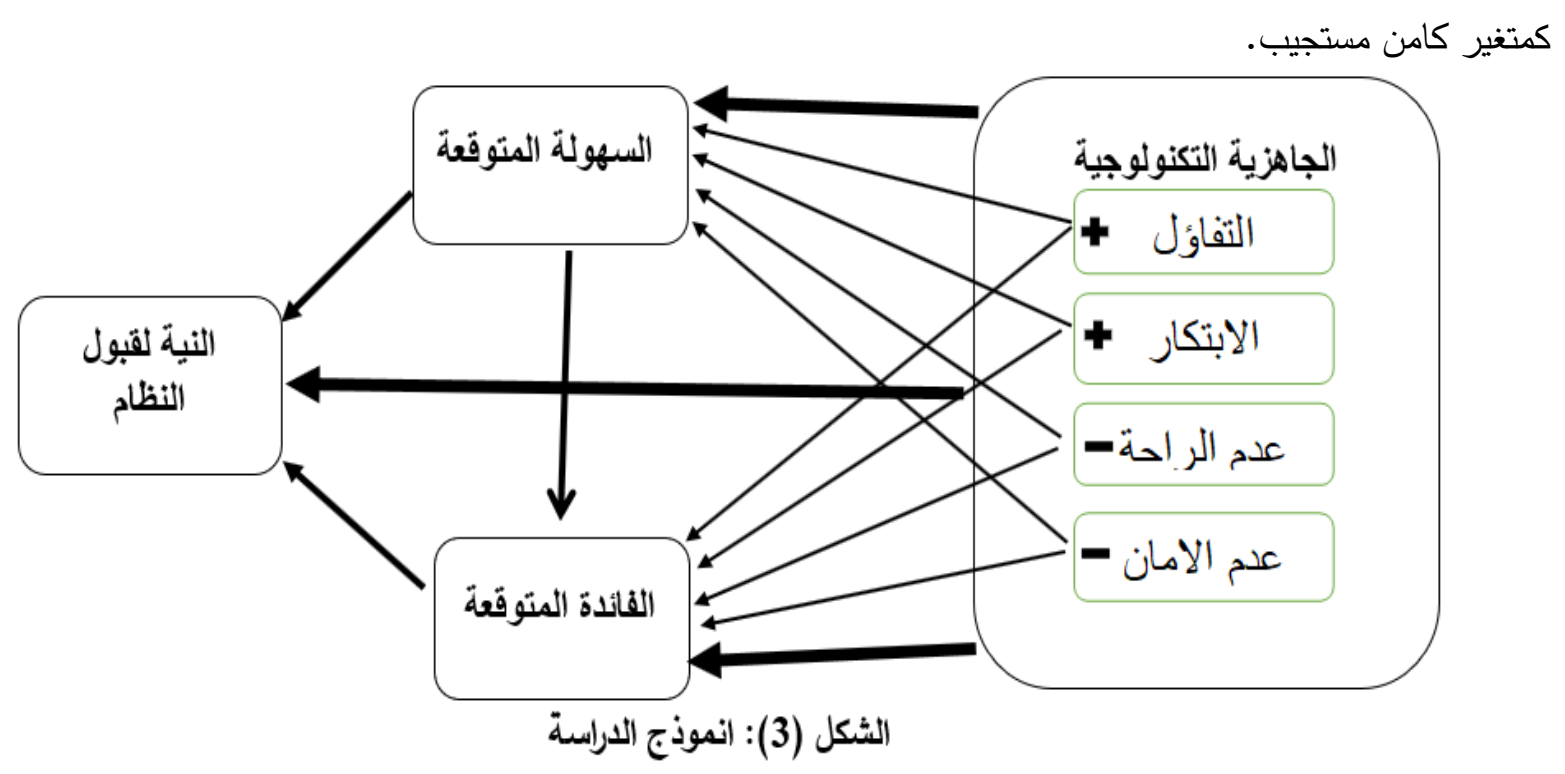

وبالاستناد إلى أنموذج الدراسة يمكن وضع الفرضيات البحثية الآتية اليوثر مستوى الجاهزية التكنولوجية للعاملين في السهولة المتوقعة لاستخدام نظام المقررات. Hr يوثر التفاؤل إيجاباً في السهولة المتوقعة لاستخدام نظام المقررات الإكتروني.

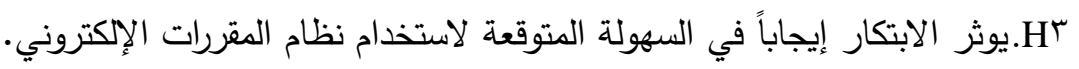

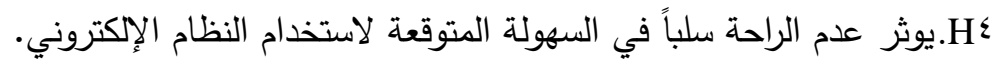
H يوثر عدم الأمان سلباً في السهولة المتوقعة لاستخدام النظام الإلكتروني.

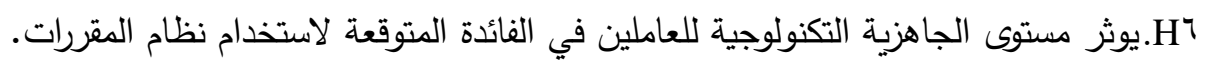

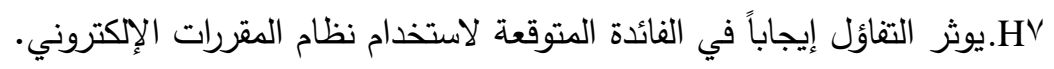

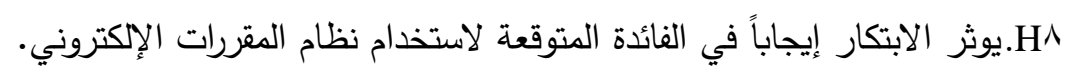

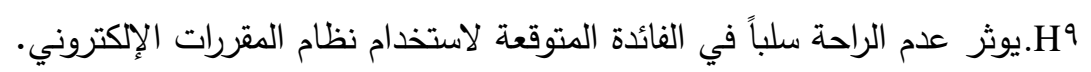


يوثر عدم الأمان سلباً في الفائدة المتوقعة لاستخدام نظام المقررات الإكتروني. .

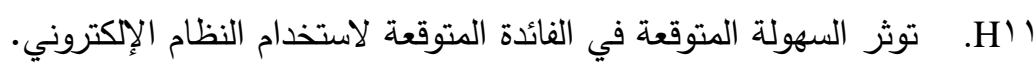

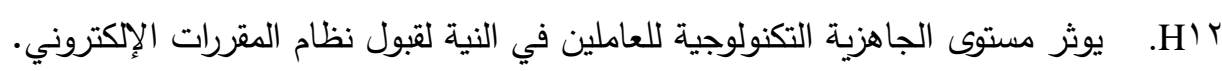

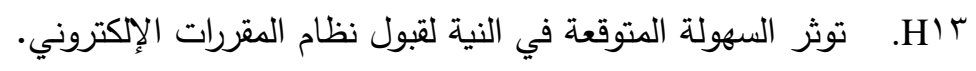

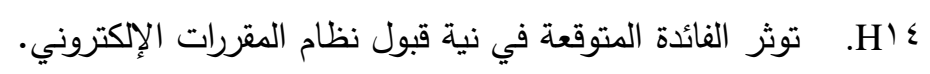
با.H ت توجد فروق معنوية لمستوى الجاهزية التكنولوجية للعاملين تعزى للمتغيرات الديمغرافية.

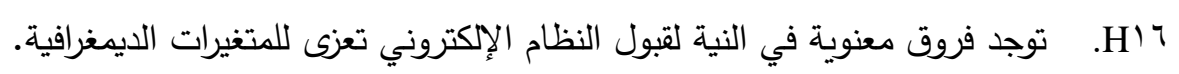
ثانياً: تحليل الخصائص الايموغرافية لمجتمع الدراسة:

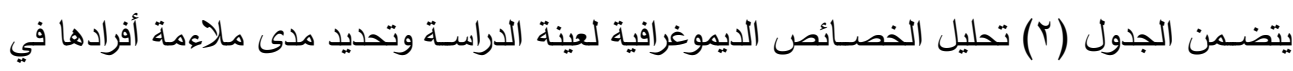

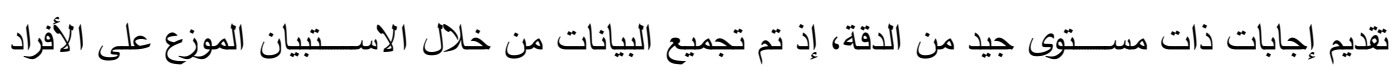
المبحوثين.

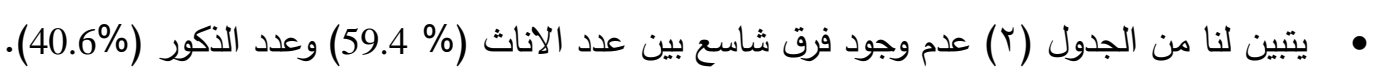

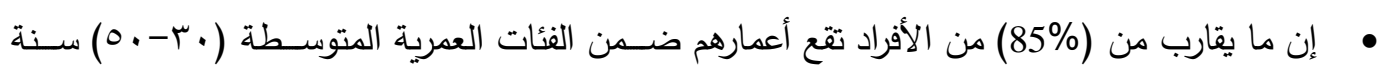

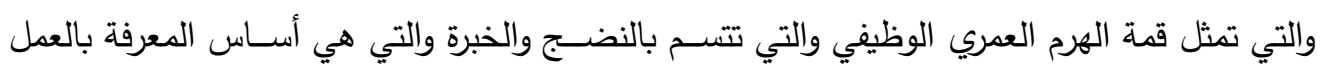
المطلوب.

إن عدد الأفراد المبحوثين الذين يحملون مؤهلات أكاديمية أولية وعليا يزيد بمرتين عن عدد الأفراد الذين لديهم مؤهلات علمية دون البكالوريوس (27\%)، وتعكس هذه النتائج درجة التأهيل والكفاءة الجيدة للأفراد المبحوثين في مجال مزاولة اعمالهم.

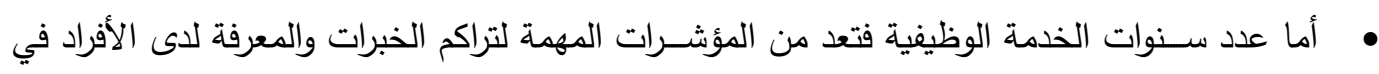

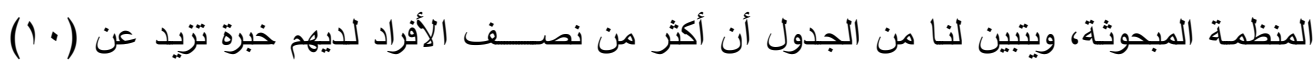

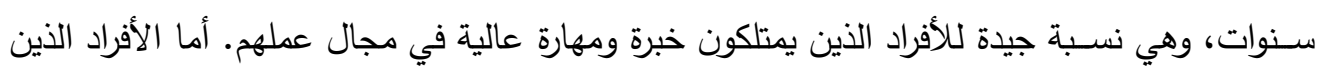

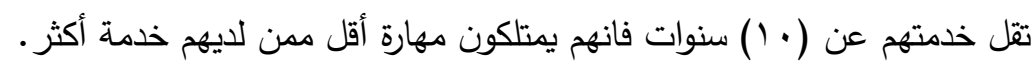

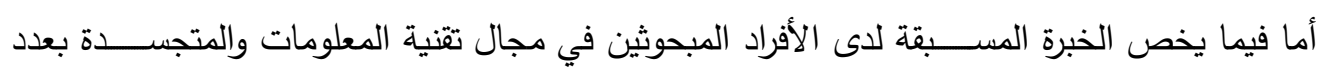

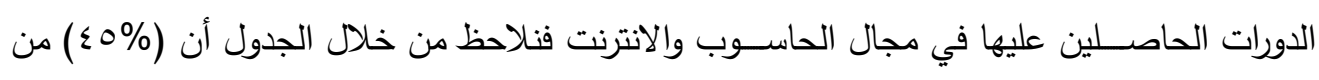
الأفراد المبحوثين غير حاصلين على أي نوع من التدريب على الحاسوب والانترنت، وهي نسبة تعادل تقريباً نصف الأفراد المبحوثين أو مجتمع الدراسة.

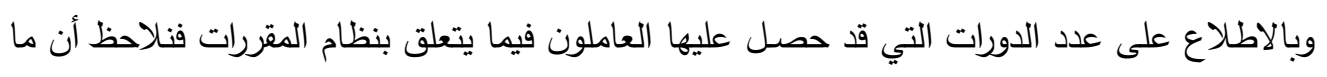
يقارب (30\%) فقط من العاملين في شـــب التســـيل قد تم زجهم في ورش ودورات خاصــــة بنظام المقررات الإككتروني، وتتجسد هذه النسية بمسؤولي شعب التسجيل من حملة الثهادة الأولية أو حملة

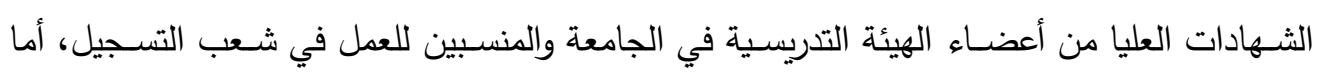




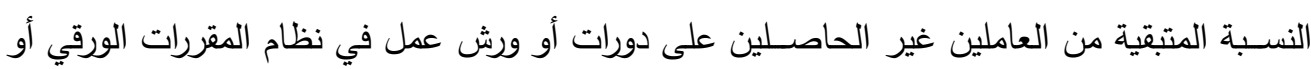
الإلكتروني فتمثل تقريباً (70\%) وهي نسبة كبيرة جداً.

الجدول (ץ): السمات والخصائص الايموغرافية للأفراد المبحوثين

\begin{tabular}{|c|c|c|c|c|c|c|c|}
\hline \multicolumn{8}{|c|}{ الجنس } \\
\hline \multicolumn{4}{|c|}{ انثى } & \multicolumn{4}{|c|}{ ذكر } \\
\hline$\%$ & \multicolumn{3}{|c|}{ 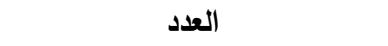 } & $\%$ & & \multicolumn{2}{|l|}{ العدد العد } \\
\hline 59.4 & \multicolumn{3}{|c|}{$\vee q$} & 40.6 & & \multicolumn{2}{|l|}{$0 \leqslant$} \\
\hline \multicolumn{8}{|c|}{ الفئات العمـرية } \\
\hline \multicolumn{2}{|c|}{ اه سنة فأكثر } & \multicolumn{2}{|c|}{ إ-- ـ - سنة } & \multicolumn{2}{|c|}{ 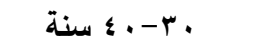 } & \multicolumn{2}{|c|}{ اقل من · س سنة } \\
\hline$\%$ & 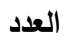 & $\%$ & 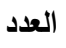 & $\%$ & 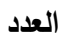 & $\%$ & 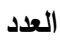 \\
\hline 18.0 & 24 & 27.0 & 36 & 54.9 & 61 & 9.0 & 12 \\
\hline \multicolumn{8}{|c|}{ التحصيل الدراسـي } \\
\hline \multicolumn{2}{|c|}{ أخرى } & \multicolumn{2}{|c|}{ دكتوراه } & \multicolumn{2}{|c|}{ ماجستير } & \multicolumn{2}{|c|}{ بكالوريوس } \\
\hline$\%$ & العدد & $\%$ & العدد & $\%$ & العدد & $\%$ & العدد \\
\hline 27.0 & 36 & 3.8 & 5 & 12.8 & 17 & 56.4 & 75 \\
\hline \multicolumn{8}{|c|}{ عدد سنوات الخدمة الوظيفية في المنظمة } \\
\hline \multicolumn{2}{|c|}{ 1 19 سنة فأكثر } & \multicolumn{2}{|c|}{$10-11$} & \multicolumn{2}{|c|}{$1 \cdot-7$} & \multicolumn{2}{|c|}{ • } \\
\hline$\%$ & 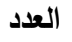 & $\%$ & 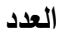 & $\%$ & 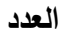 & $\%$ & 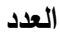 \\
\hline 39.9 & 53 & 21.8 & 29 & 28.6 & 38 & 9.8 & 13 \\
\hline \multicolumn{8}{|c|}{ عدد الدورات في مجال الحاسوب وتكنولوجيا المعلومات } \\
\hline \multicolumn{2}{|c|}{ r دورات فأكثر } & \multicolumn{4}{|c|}{ 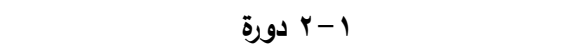 } & \multicolumn{2}{|c|}{ لم أشارك باي دورة } \\
\hline$\%$ & العدد & \multicolumn{2}{|c|}{$\%$} & \multicolumn{2}{|c|}{ العدد } & $\%$ & العدد \\
\hline 18.0 & 24 & \multicolumn{2}{|c|}{36.8} & \multicolumn{2}{|c|}{49} & 45.1 & 60 \\
\hline \multicolumn{8}{|c|}{ عدد الدورات او ورشات العمل في مجال نظام المقررات الإكتروني } \\
\hline \multicolumn{2}{|c|}{ 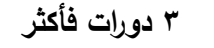 } & \multicolumn{4}{|c|}{ 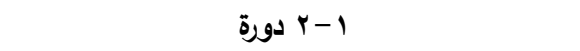 } & 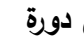 & 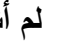 \\
\hline$\%$ & العدد & & & & & $\%$ & العدد \\
\hline 6.8 & 9 & & & & & 68.4 & 91 \\
\hline
\end{tabular}

المصدر: عمل الباحث بالاستتاد على نتائج

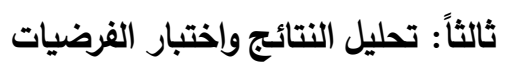

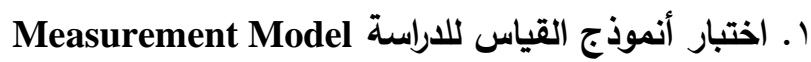

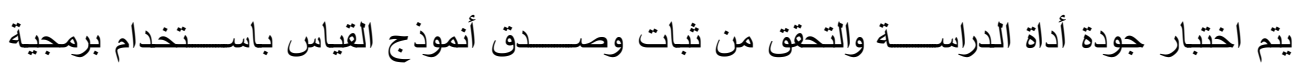
(Ringle, Wende, \& Becker, 2015) (SmartPLS) كرونباخ والثبات المركب وحسـاب الصـدق التقريبي (متوسط قيم التباين المفسر AVE وقيم التشبع) وهو ما يوضحه الجدول (r)، فضلاً عن حساب الصدق التمييزي (الجذر التربيعي لــ AVE والتشبعات المتقاطعة)

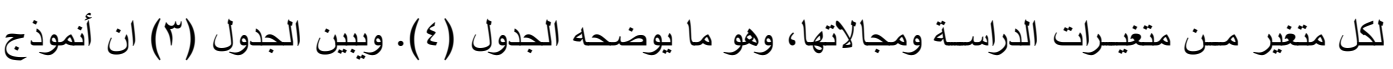


القياس يتمتع بالمصـــاقية والثبات الجيد حيث كانت جميع قيم التثــبعات والثبات المركب أكبر من القيمة

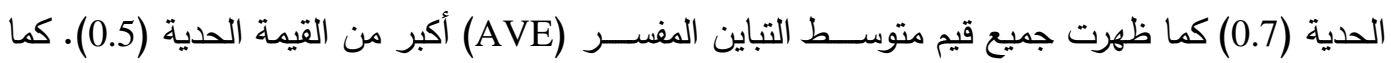

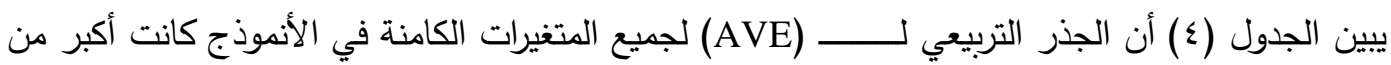
Hair, Hult, Ringle, \& Sarstedt, 2017; Fornell and Larker's, الارتبـاطـات المرافقـة للمتغيرات

.$(1981)$

\begin{tabular}{|c|c|c|c|c|c|c|}
\hline متوسط التباين & المركب * الثبات & 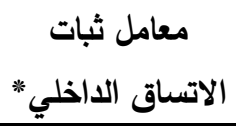 & ألفا كرونباخ معامل & التشبعات & 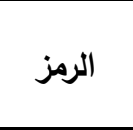 & البعد البع \\
\hline 0.773 & 0.932 & 0.903 & 0.902 & $\begin{array}{l}0.891 \\
0.887 \\
0.892 \\
0.846\end{array}$ & $\begin{array}{l}\text { OPT1 } \\
\text { OPT2 } \\
\text { OPT3 } \\
\text { OPT4 }\end{array}$ & التفاؤل \\
\hline 0.749 & 0.923 & 0.890 & 0.888 & $\begin{array}{l}0.834 \\
0.891 \\
0.872 \\
0.864\end{array}$ & $\begin{array}{l}\text { INN1 } \\
\text { INN2 } \\
\text { INN3 } \\
\text { INN4 }\end{array}$ & الابتكار \\
\hline 0.764 & 0.928 & 0.898 & 0.897 & $\begin{array}{l}0.894 \\
0.908 \\
0.847 \\
0.846\end{array}$ & $\begin{array}{l}\text { DIS1 } \\
\text { DIS2 } \\
\text { DIS3 } \\
\text { DIS4 }\end{array}$ & عدم الراحة \\
\hline 0.738 & 0.918 & 0.887 & 0.882 & $\begin{array}{l}0.898 \\
0.869 \\
0.827 \\
0.841\end{array}$ & $\begin{array}{l}\text { INS1 } \\
\text { INS2 } \\
\text { INS3 } \\
\text { INS4 }\end{array}$ & عدم الامان \\
\hline 0.782 & 0.935 & 0.907 & 0.907 & $\begin{array}{l}0.893 \\
0.902 \\
0.869 \\
0.872\end{array}$ & $\begin{array}{l}\text { EOU1 } \\
\text { EOU2 } \\
\text { EOU3 } \\
\text { EOU4 }\end{array}$ & السهولة المتوقعة \\
\hline 0.750 & 0.923 & 0.892 & 0.889 & $\begin{array}{l}0.876 \\
0.899 \\
0.874 \\
0.814\end{array}$ & $\begin{array}{l}\text { USEF1 } \\
\text { USEF2 } \\
\text { USEF3 } \\
\text { USEF4 }\end{array}$ & الفائدة المتوقعة \\
\hline 0.828 & 0.935 & 0.896 & 0.896 & $\begin{array}{l}0.911 \\
0.920 \\
0.900\end{array}$ & $\begin{array}{l}\text { INT1 } \\
\text { INT2 } \\
\text { INT3 }\end{array}$ & نية الاستخدام \\
\hline
\end{tabular}

المصدر: عمل الباحث بالاستتاد إلى نتائج SmartPLS

الجدول (4): قيم الصدق التمييزي لأنموذج القياس

\begin{tabular}{|c|c|c|c|c|c|c|c|}
\hline نية & علدم & عالأمان & الفائدة & المتوقهولة & التفاؤل & الابتكار & الأبعاد \\
\hline & & & & & & 0.866 & الابتكار \\
\hline & & & & & 0.879 & 0.772 & التفاؤل \\
\hline
\end{tabular}




\begin{tabular}{|c|c|c|c|c|c|c|c|}
\hline نية & عدم & عدم & الأفائدة & السهوتلة & التفاؤل & الابتكار & الأبعاد \\
\hline & & & & 0.884 & 0.822 & 0.767 & السهولة المتوقعة \\
\hline & & & 0.866 & 0.836 & 0.703 & 0.755 & الفائدة المتوقعة \\
\hline & & 0.859 & 0.694 & 0.715 & 0.787 & 0.855 & عدم الامان \\
\hline & 0.874 & 0.764 & 0.714 & 0.834 & 0.814 & 0.834 & عدم الراحة \\
\hline 0.910 & 0.781 & 0.706 & 0.837 & 0.880 & 0.727 & 0.771 & نية الاستخدام \\
\hline
\end{tabular}

SmartPLS المصدر: عمل الباحث بالاستتاد إلى نتائج

r. T. اختبار الأنموذج البنائي للدراسة Structural Model بعد اختبار أنموذج القياس والتأكد من الصـــدق والثبات يتم اختبار الأنموذج البنائي للدراســــة عبر اختبار الفرضـــيات لهذه الدراســــة باســـتخدام تحليل المعطيات من خلال تطبيق معادلة (نمذجة المعادلة الهيكلية) وبطريقة المربعات الصـــغرى الجزئية (PLS) لتحليل تأثير الجاهزية التكنولوجية للعاملين بأبعادها الأربعة (التفاؤل، الابتكار ، عدم الراحة، عدم الأمان) على سهولة الاستخدام المتوقعة والفائدة المتوقعة لنظام

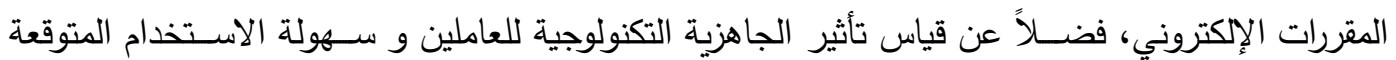
والفائدة المتوقعة لنظام المقررات الإكتروني على النية الســلـوكية لقبول نظام المقررات الإلكتروني. ويمكن

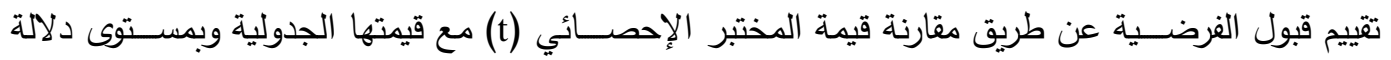

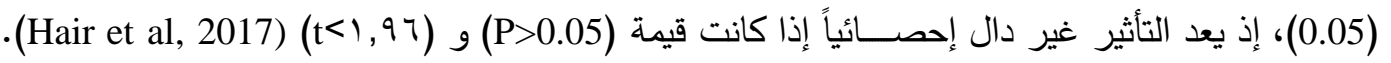
ويلخص الجدول (5) جميع الفرضــيات المســتخدمة في هذه الدراســة ونتيجة القرار الخاص بها، كما يبين الشكل (4) مسارات التأثير الفرعية لأنموذج الدراسة عبر اختبار الفرضيات ( - H2- H5, H7- H11, H13 H14) والثكل (5) يظهر مسارات التأثير الكلية لأنموذج الدراسة عبر اختبار الفرضيات (H1,H6,H12). الجدول (5): مسار التأثير الكلي

\begin{tabular}{|c|c|c|c|c|c|c|}
\hline 酒 & 时 & 时 & $\frac{\bar{d}}{\bar{g}} \quad \frac{\xi_{z}}{\hat{y}_{z}}$ & 果 & المتغير المستقل -> المتغير التابع & 牙 \\
\hline قبول & 0.000 & 24.377 & 0.035 & 0.852 & الجاهزية التكنولوجية ->> السهولة المتوقعة & H1 \\
\hline 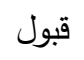 & 0.000 & 4.908 & 0.083 & 0.408 & التفاؤل -> السهولة المتوقعة & $\mathrm{H} 2$ \\
\hline 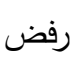 & 0.389 & 0.862 & 0.168 & 0.145 & الابتكار ->> السهولة المتوقعة & H3 \\
\hline 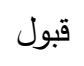 & 0.003 & 2.990 & 0.141 & -0.421 & عدم الراحة -> السهولة المتوقعة & H4 \\
\hline 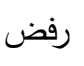 & 0.695 & 0.392 & 0.132 & 0.052 & عدم الامان ->> السهولة المتوقعة & H5 \\
\hline قبول & 0.000 & 14.641 & 0.053 & 0.777 & الجاهزية التكنولوجية ->> الفائدة المتوقعة & H6 \\
\hline
\end{tabular}


دور الجاهزية التكنولوجية في قبول نظام المقردات........

الصميدعي

\begin{tabular}{|c|c|c|c|c|c|c|}
\hline 深 & 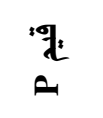 & - & 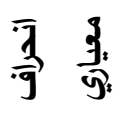 & ". & المتغير المستقل -> المتغير التابع & 牙 \\
\hline 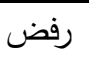 & 0.537 & 0.617 & 0.126 & 0.078 & التفاؤل ->> الفائدة المتوقعة & $\mathrm{H} 7$ \\
\hline 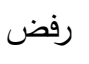 & 0.447 & 0.761 & 0.114 & 0.086 & الابتكار -> الفائدة المتوقعة & H8 \\
\hline 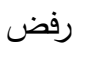 & 0.190 & 1.310 & 0.123 & -0.161 & عدم الراحة ->> الفائدة المتوقعة & H9 \\
\hline 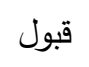 & 0.048 & 1.979 & 0.158 & -0.313 & عدم الامان -> الفائدة المتوقعة & H10 \\
\hline ق ق قبول & 0.000 & 5.064 & 0.145 & 0.732 & السهولة المتوقعة -> الفائدة المتوقعة & H11 \\
\hline 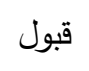 & 0.000 & 15.473 & 0.052 & 0.810 & الجاهزية التكنولوجية -> نية الاستخدام & $\mathrm{H} 12$ \\
\hline 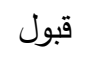 & 0.000 & 5.894 & 0.102 & 0.598 & السهولة المتوقعة -> نية الاستخدام & $\mathrm{H} 13$ \\
\hline ق ق قبول & 0.001 & 3.473 & 0.097 & 0.336 & الفائدة المتوقعة -> نية الاستخدام & H14 \\
\hline
\end{tabular}

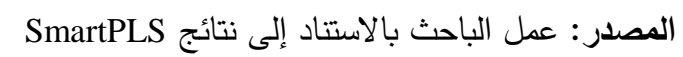

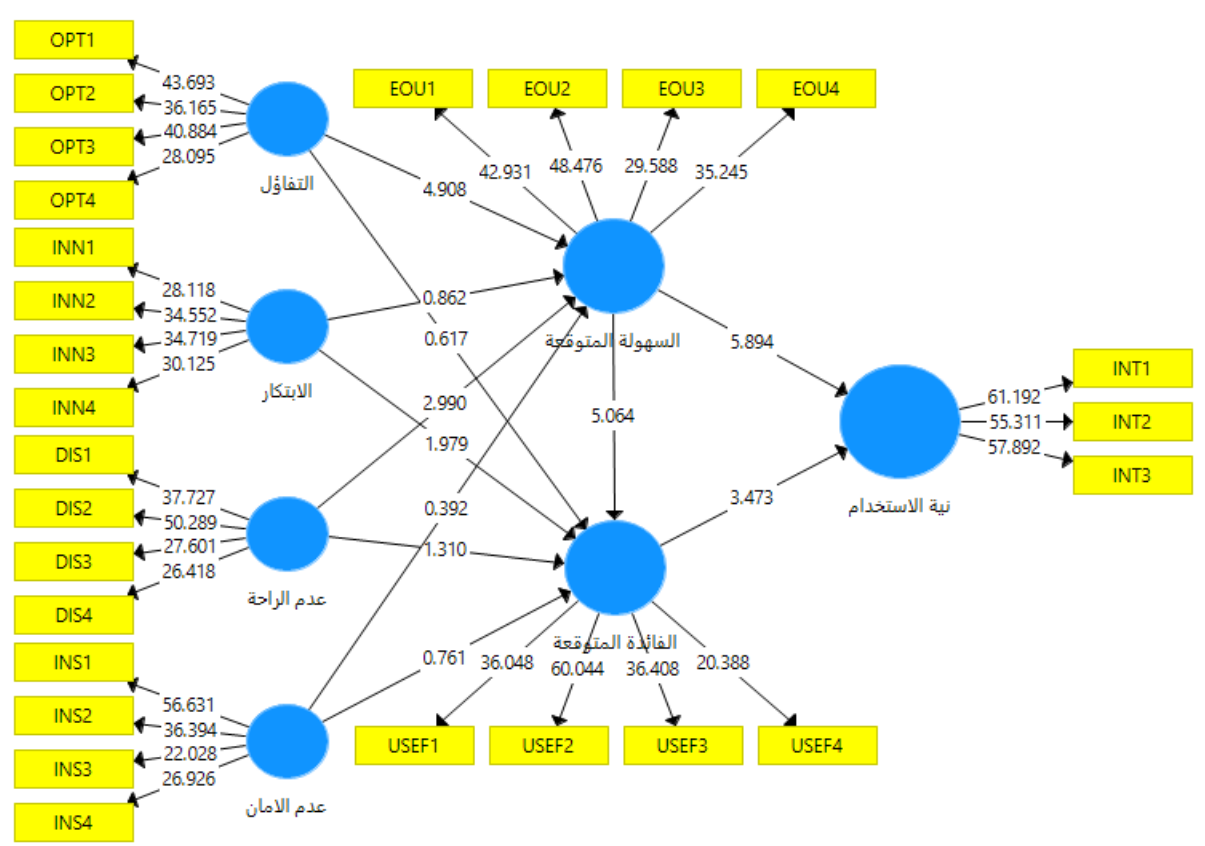

الشكل (؛ ): مسارات التأثير لمؤشرات الجاهزية التكنولوجية المصدر: عمل الباحث بالاستتاد إلى نتائج SmartPLS 


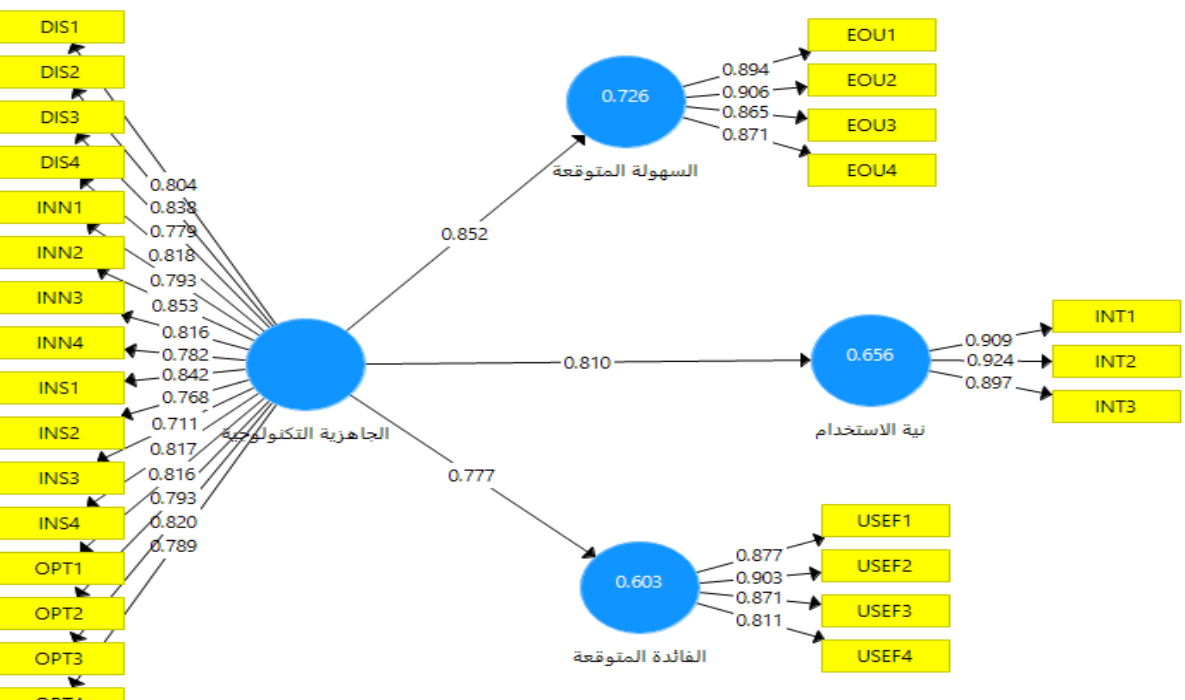

الثكل (0): مسار التأثير الكلي لمؤشر الجاهزية التكنولوجية المصدر : عمل الباحث بالاستناد إلى نتائج SmartPLS وفي إطار اختبار فرضسيات الدراسـة يتبين لنا من خلال الجدول (5) أن الجاهزية التكنولوجية للأفراد

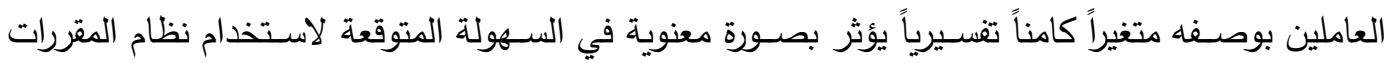

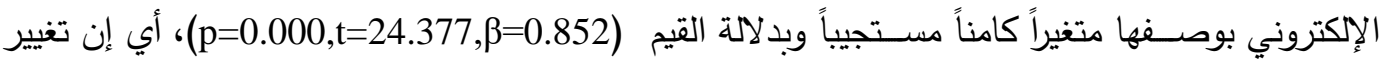
جاهزية الأفراد بوحدة واحدة ســـوف يغير بمدى ادراك الأفراد لســــهولة الذظام بمقدار (0.852)، كما ان الجاهزية التكنولوجية تقسـر تقريباً (73\%) من التغير الحاصــل في الســهولة المتوقعة بدلالة قيمة معامل

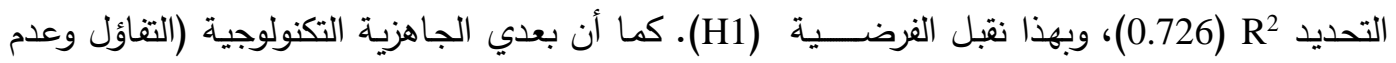

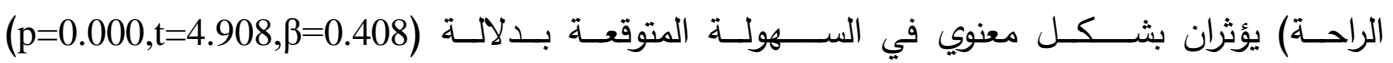

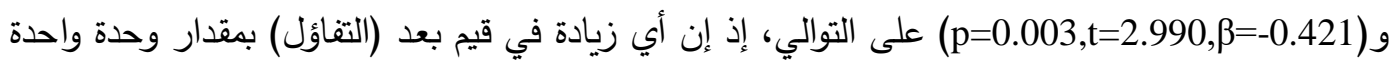
سوف يزيد من مدى إدراك الأفراد لسهولة النظام بمقدار (0.408) وأي زيادة في قيم بعد (عدم الراحة) بمقدار

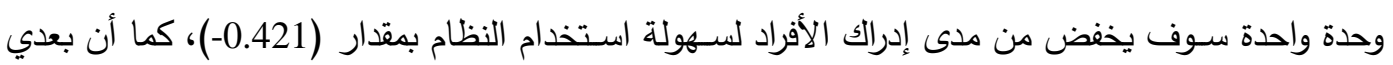
(التفاؤل وعدم الراحة) يفسران (73\%) من التغير الحاصل في السـهولة المتوقعة بدلالة قيمة معامل التحديد

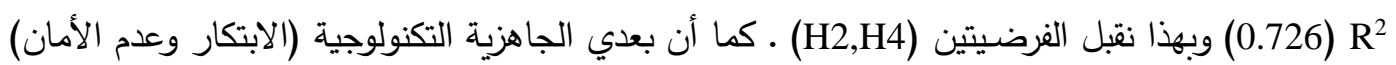

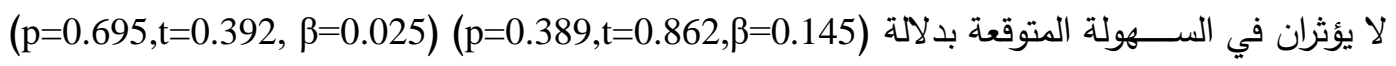
على التوالي، وبهذا نرفض الفرضيتين (H3,H5) ونقبل الفرضية البديلة.

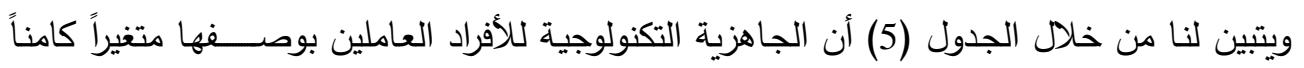

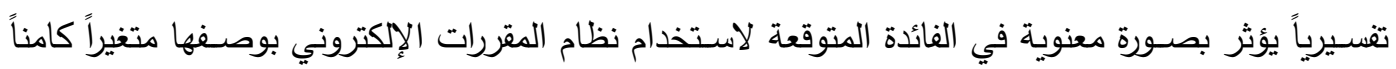

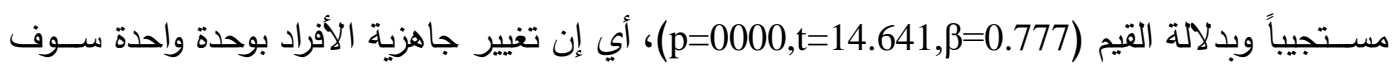

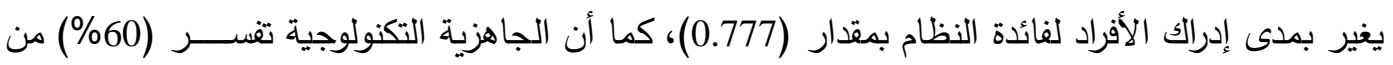


التغير الحاصل في الفائدة المتوقعة بدلالة قيمة معامل التحديد R2 (0.60)، وبهذا نقبل الفرضية (H6). كما

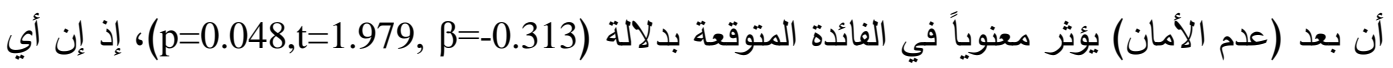

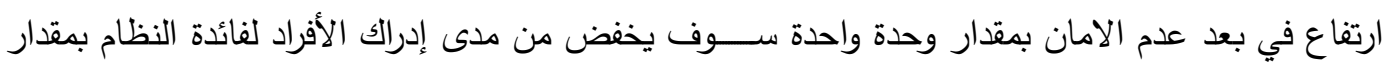

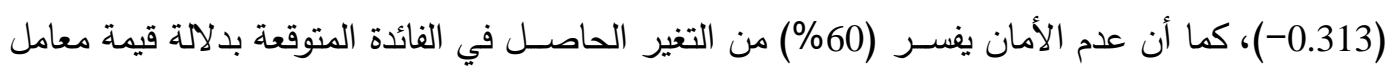
التحديد R20.60 R2)، وبهذا نقبل الفرضية (H10). أما الأبعاد التي تتمثل بـ (التفاؤل والابتكار وعدم الراحة)

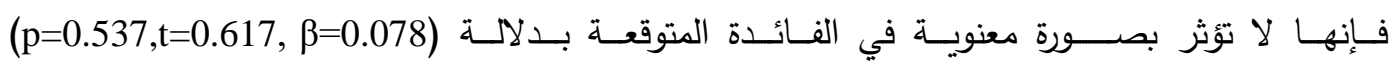
على التوالي، وبهذا نرفض الفرضسيات (p=0.190,t=1.310, $\beta=-0.161)$ (p=0.447,t=0.761, $\beta=0.086)$ (H7,H8,H9) ويتبين لنا من خلال الجدول (5) أن الجاهزية التكنولوجية للأفراد العاملين والسـهولة والفائدة المتوقعة بوصفها متغيرات كامنة تفسيرية تؤثر بصورة معنوية في نية قبول نظام المقررات الإكتروني بوصفها متغيراً

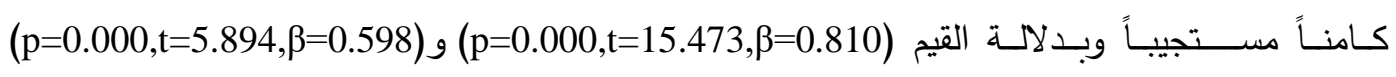
و) عل0.001,t=3.473, ع=0.336) على التوالي، أي إن التغيير في جاهزية الأفراد أو السـهولة المتوقعة أو

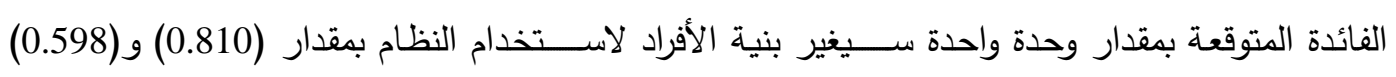
و(0.336) على التوالي، وتفسر هذه الأبعاد الثلاثة ما يقارب (66\%) من التغير الحاصل في نية الاستخدام

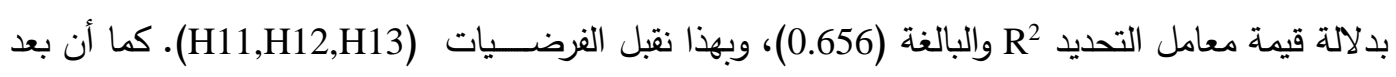

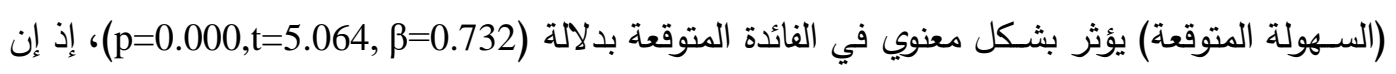
أي تغيير في بعد السـهولة المتوقعة بمقدار وحدة واحدة سـوف يغير بمدى إدراك الأفراد لفائدة النظام بمقدار

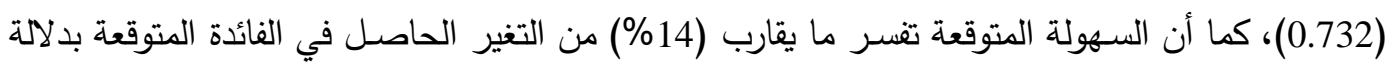
قيمة معامل التحديد R² الكلية والبالغة (0.739)، وبهذا نقبل الفرضية (H14).

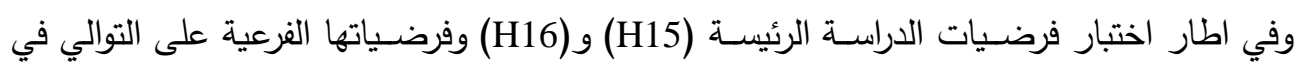

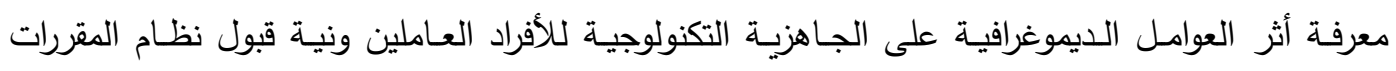

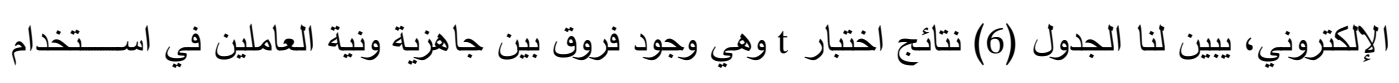

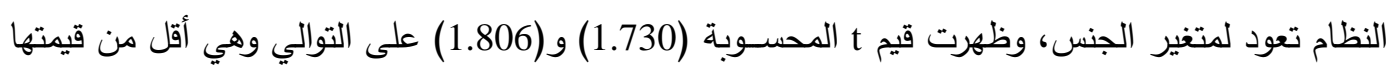

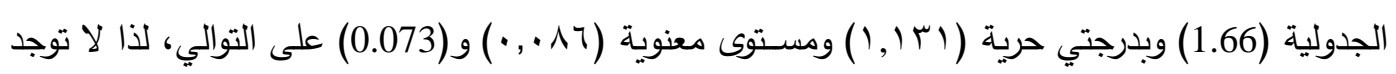

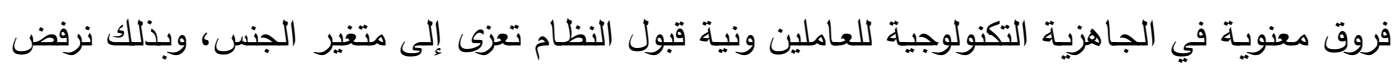

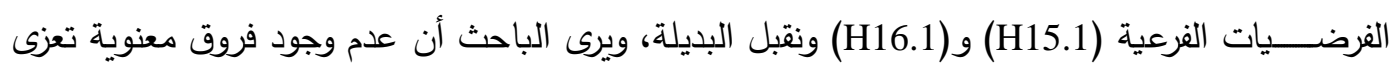

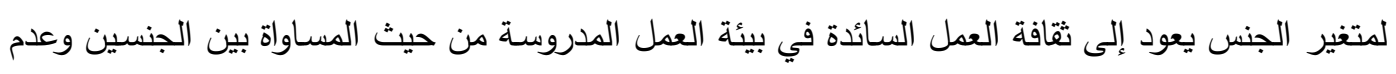
الاختلاف في المهام والواجبات الوظيفية، ويعزز ذلك عدم وجود اختلاف كبير بين إعداد العاملين من كلا

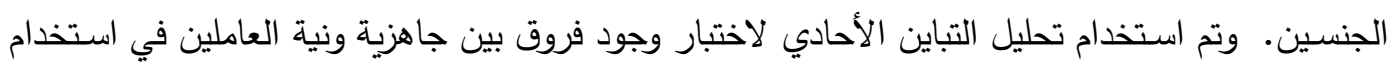

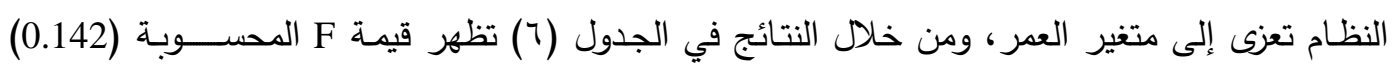


و(0.588) على التوالي وهي أقل من قيمتها الجدولية (2.67) وبدرجتي حرية (3,129) ومســـتوى معنوية (0.868) و(0.557) على التوالي، لذا لا توجد فروق معنوية في الجاهزيـة التكنولوجية للعاملين ونية قبول

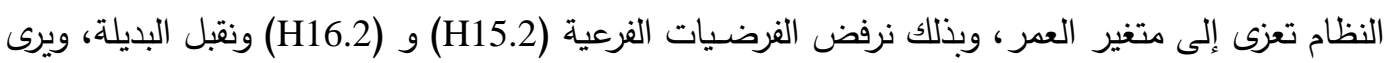
الباحث أن عدم وجود فروق معنوية تعزى لمتغير العمر يعود إلى أن أغلب الأفراد المبحوثين تقع أعمارهم

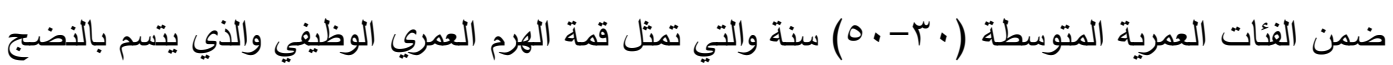
والخبرة في أداء العمل المطلوب. كما تم اسـتخدام تحليل التباين الأحادي لاختبار وجود فروق بين جاهزية ونية العاملين في اسـتخدام

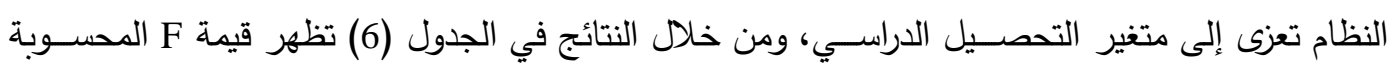

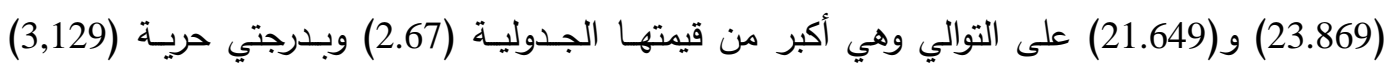
ومسـتوى معنوية (0.000) على التوالي، لذا توجد فروق معنوية في الجاهزية التكنولوجية للعاملين ونية قبول

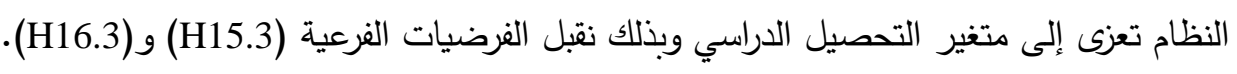
ويبين الجدول (T) نتائج تحليل التباين الأحادي لاختبار وجود فروق بين جاهزية ونية العاملين في

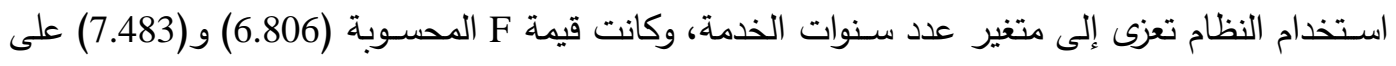

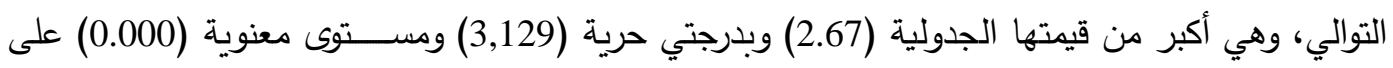

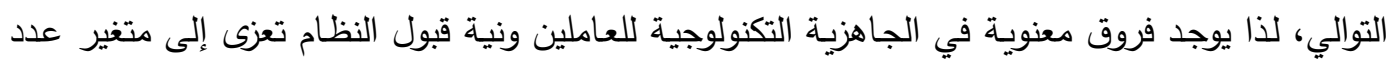
سنوات الخدمة وبذلك نقبل الفرضيات الفرعية (H15.4) و (H16.4). 
الجدول (6): نتائج اختبار t والتباين الأحادي لإجابات الأفراد المبحوثين لمعرفة أثر العوامل الايموغرافية على الجاهزية التكنولوجية ونية قبول نظام المقررات الإكتروني لإباني

\begin{tabular}{|c|c|c|c|c|c|c|c|}
\hline القراد & 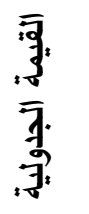 & $\frac{3}{7}$ & $\begin{array}{l}: \frac{7}{2} \\
\frac{7}{3} \\
: \frac{7}{2}\end{array}$ & 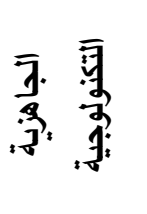 & الاختبارات & الفرضية & عنوان المحور \\
\hline رفض الفرضية & \multirow{2}{*}{1.66} & 1 & 1.806 & 1.730 & اختبار T & H15.1 & \multirow{2}{*}{ الجنس } \\
\hline لايوجد فروق & & M & 0.073 & $\cdot \cdot \cdot 14$ & Sig. & H16.1 & \\
\hline رفض الفرضية & \multirow{6}{*}{2.67} & r & 0.588 & 0.142 & F اختبار F & H15.2 & \multirow{2}{*}{ الفئات العمرية } \\
\hline لايوجد فروق & & $1 r^{\prime}$ & 0.557 & 0.868 & Sig. & H16.2 & \\
\hline قبول الفرضية & & r & 21.649 & 23.869 & F اختبار F & H15.3 & \multirow{2}{*}{ التحصيل الدراسي } \\
\hline يوجد فروق & & irq & 0.000 & 0.000 & Sig. & H16.3 & \\
\hline قبول الفرضية & & r & 7.483 & 6.806 & F اختبار F & H15.4 & \multirow{2}{*}{ عدد سنوات الخدمة } \\
\hline يوجد فروق & & 149 & 0.000 & 0.000 & Sig. & H16.4 & \\
\hline قبول الفرضية & \multirow{4}{*}{3.07} & r & 15.079 & 22.665 & F اختبار F & H15.5 & \multirow{2}{*}{ دورات في الحاسوب } \\
\hline يوجد فروق & & ir. & 0.000 & 0.000 & Sig. & H16.5 & \\
\hline قبول الفرضية & & r & 43.542 & 46.185 & F اختبار F & H15.60 & دورات في نظــام الم \\
\hline يوجد فروق & & וr. & 0.000 & 0.000 & Sig. & H16.6 & الإكتروني \\
\hline
\end{tabular}

ومن خلال الجدول (6) تظهر نتائج تحليل التباين الأحادي لاختبار وجود فروق بين جاهزية ونية

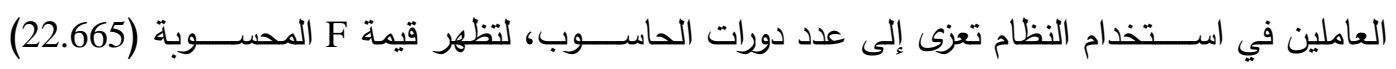

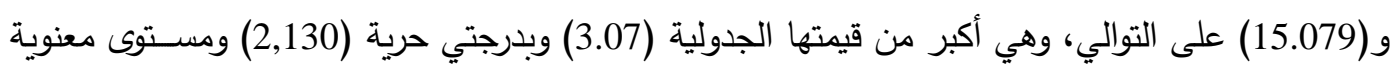
(0.000) على التوالي، لذا توجد فروق معنوية في الجاهزية التكنولوجية للعاملين ونية قبول النظام تعزى إلى دونى

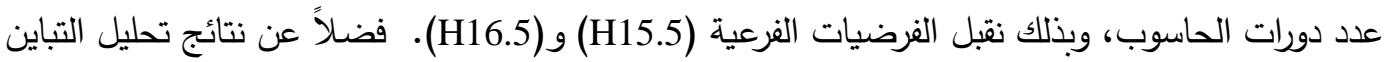
الأحادي لاختبار وجود فروق بين جاهزية ونية العاملين في اســـتخدام النظام تعزى إلى الدورات في نظام المقررات، إذ كانت قيمة F المحســـوبة (46.185) و(43.542) على التوالي وهي أكبر من قيمتها الجدولية

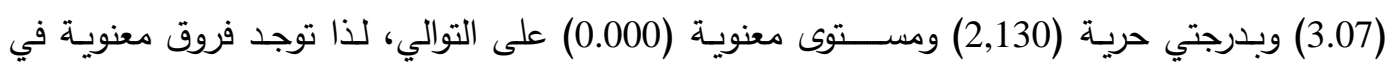
الجاهزيـة التكنولوجية للعاملين ونية قبول النظام تعزى إلى عدد الدورات في نظام المقررات، وبذلك نقبل الفرضيات الفرعية (H15.6) و (H16.6).

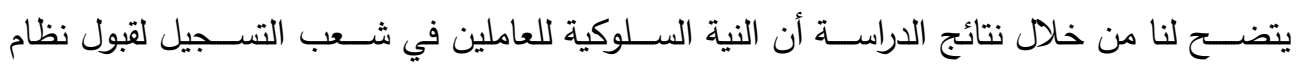

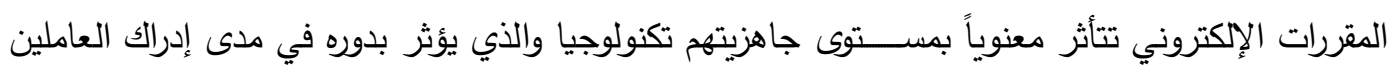

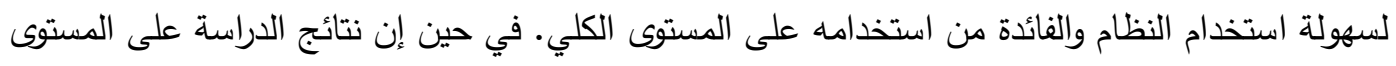

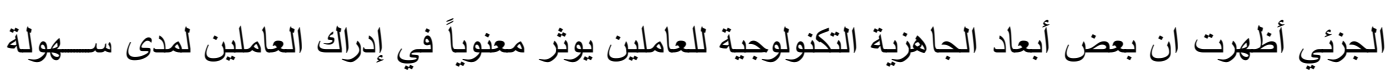


استخدام نظام المقررات الإكتروني، إذ كلما ازداد شعور الأفراد بالتفاؤل والنظرة بإيجابية للتكنولوجيا الحديثة

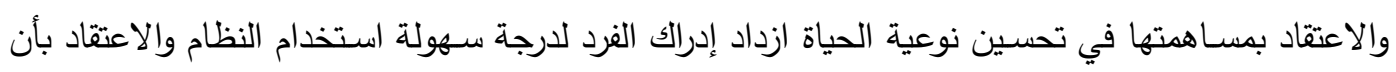
استخدام النظام سيكون خاليًا من الجهد البدني والعقلي، في حين يقل هذا الاعتقاد بازدياد مستوى عدم الراحة

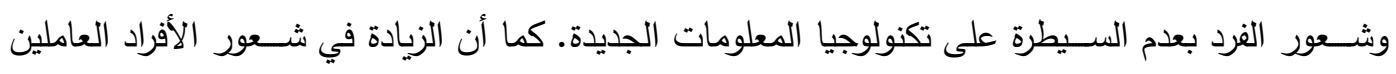

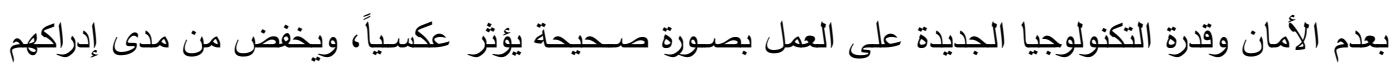

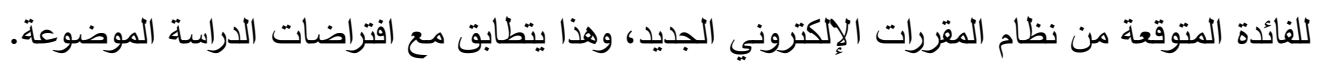

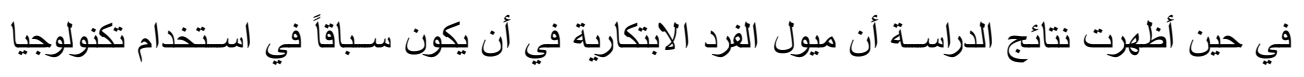

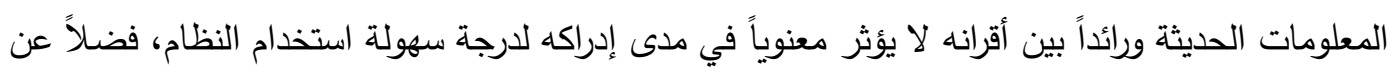

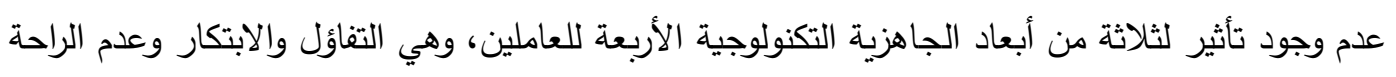

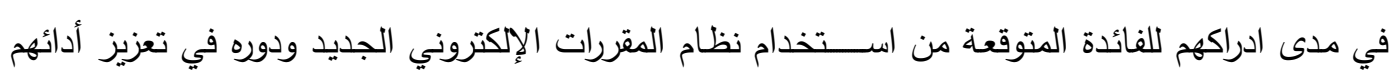

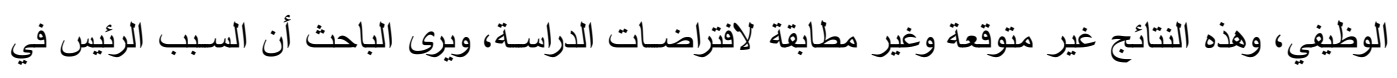
ظهور هذه النتائج هو الاعتقاد القوي والمسبق لدى عيد عينة الدراسـة في فثـل نظام المقررات الدراسية كنظام

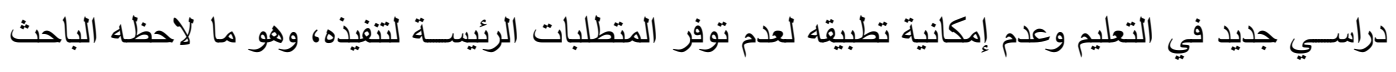
عند توزيع استمارة الاستبيان والنقاش مع معظم العاملين في شعب التسجيل، وهو ما أثر في مدى قناعناتهاتهم

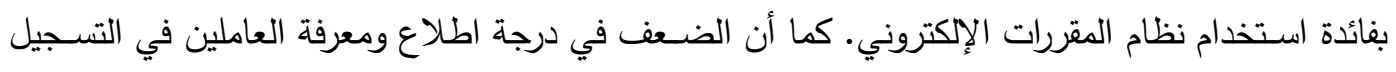
بنظام المقررات الإكتروني ودورهم في تطبيقه عزز هذا الاتجاه، حيث أظهرت نتائج التحليل أن هناك فروقاً معنوية في مستوى جاهزية العاملين ونيتهم السلوكية لقبول نظام المقررات تعزى لعدد الدورات التدريبية التي لتئي

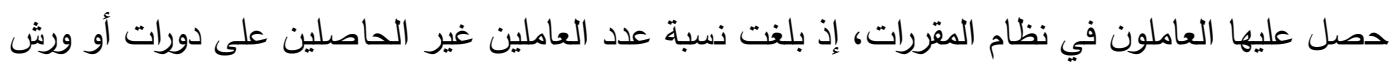
عمل في نظام المقررات الإكتروني ما يقارب سبعين في المئة وهي نسبة مرتفعة. الاستنتاجات

ا. إن معظم العاملين في شـعب التسـجيل في الجامعة هم ضــمن الفئات العمرية التي تتســ بالنضـــج

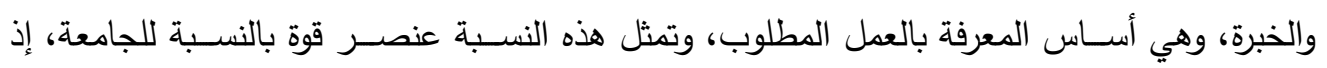

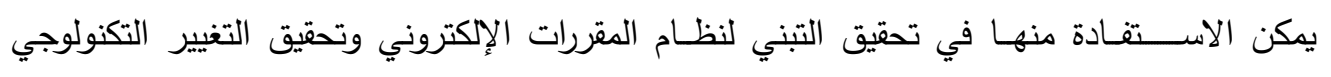
المطلوب. r. إن معظم العاملين في شـعب التسـجيل لا يمتلكون أي تصـور مسبق عن نظام المقررات الإلكتروني،

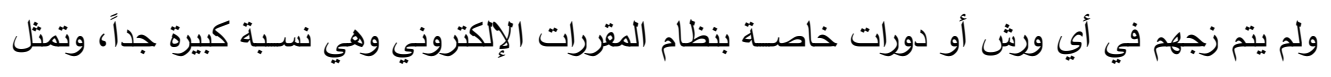

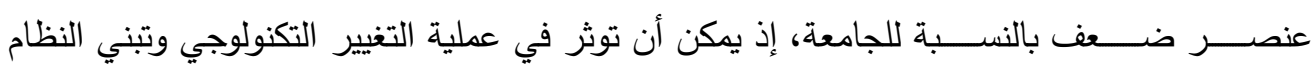
الإلكتروني المطلوب. 
r. هناك تأثير معنوي لمســـتوى الجاهزية التكنولوجية للعاملين في التعامل مع النظم والتكنولوجيا الجديدة

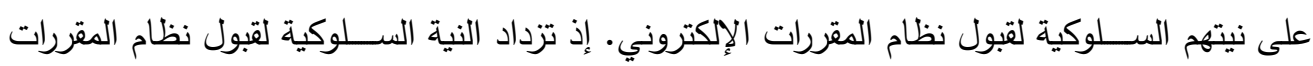
الإلكتروني بازدياد مستوى الجاهزية للأفراد العاملين.

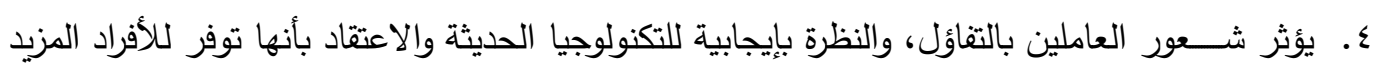
من التحكم والمرونة والكفاءة في حياتهم العامة، بشكل إيجابي على مدى إدراكهم لسهولة استخدام نظام

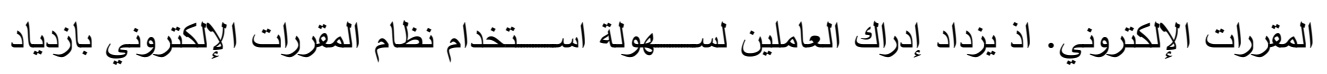
مستوى شعورهم بالتفاؤل والرضى عن التكنولوجيا الجديدة. ه. يؤثر شعور العاملين بعدم الراحة والإرهاق وعدم القدرة في السيطرة على التكنولوجيا الجديدة والتضـايق

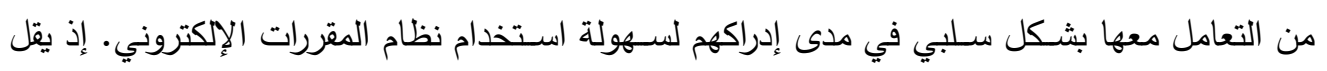
إدراك العاملين لسهولة استخدام نظام المقررات الإكتروني بازدياد مستوى شعورهم بعدم الراحة والإرهاق والتضايق من التعامل مع التكنولوجيا الجديدة.

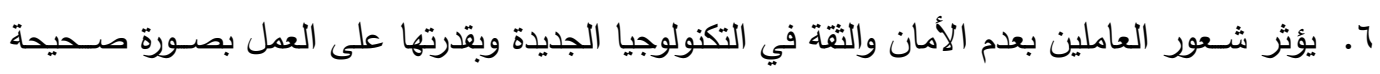

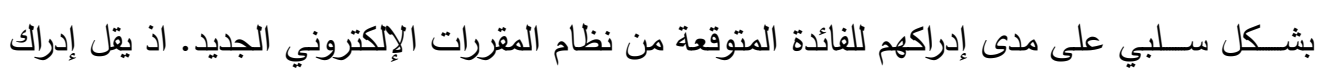

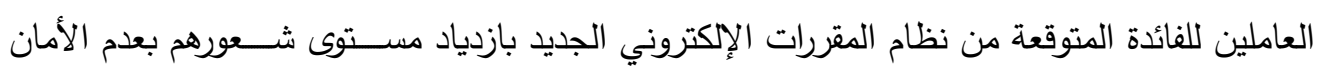
والثقة في التكنولوجيا الجديدة.

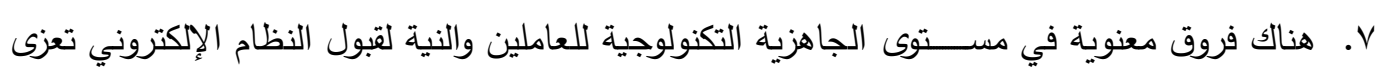

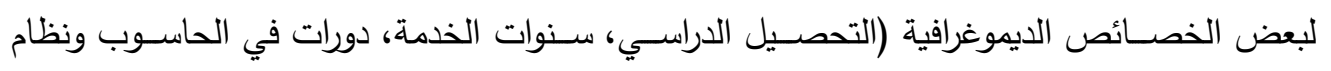

$$
\text { المقررات الإلكتروني). }
$$

1. ضــــرورة القيام بتحليل ثقافة العمل الســـائدة بين العاملين في الجامعة لمعرفة قناعاتهم تجاه التغيير

$$
\text { التكنولوجي في عمهم وقياس مدى جاهزيتهم قبل الشروع بتطبيق أي نظام إلكتروني جديد. }
$$

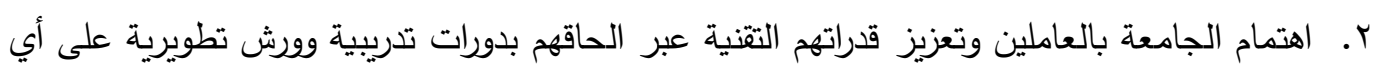

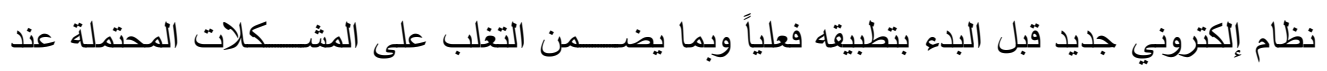

$$
\text { الاستخدام الفعلي للنظام مستقبلاً. }
$$

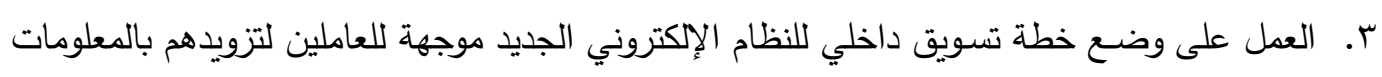

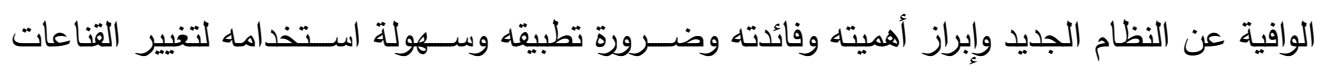

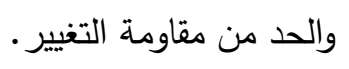
ـ. ــ زيادة الاهتمام بالعاملين والقضـــــاء على هاجس الخوف الذي ينتاب الكثير منهم لعدم الثقة بالنظم

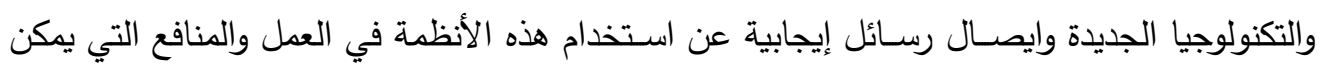


أن تتحقق من خلال تبنيها، مع التأكيد على عدم تأثير هذه الأنظمـة في تغيير المراكز الوظيفية

$$
\text { للعاملين. }
$$

๑. ضـــرورة الأخذ بعين الاعتبار الفروق الفردية بين العاملين فيما يتعلق بالمســتوى التعليمي والخبرة

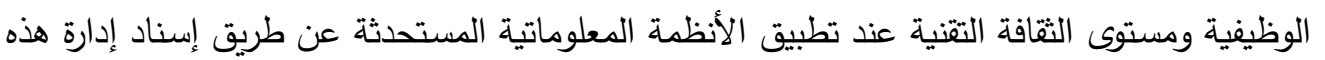
الأنظمة للعاملين الحاصـلين على مســتوى تعليمي أو خبرة وظيفية عالية مع تركيز الدورات التدريبية

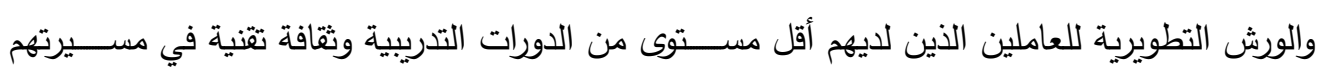
الوظيفية.

\section{شكر وتقدير}

يثـــــــــــر الباحث جامعة الموصل وجميع العاملين في شعب التسجيل والثئون الطلابية لتعاونهم وتزويده بالبيانات والمعلومات المطلوبة في الدراسـة. فضـلاً عن تقديم الثكر للبروفسور (Parasuraman) من جامعة ميامي والسـيد (Colby) مؤسـس شـركة (Rockbridge Associates, Inc. لتزويده بترخيص رســي لاســخدام مقياس الجاهزيـة التكنولوجية (TRI 2.0) لأغراض البحث العلمي والمحمي بحقوق الطبع

$$
\begin{aligned}
& \text { لا يوجد أي نوع من أنواع تضارب المصالح. تضارب المصالح } \\
& \text { تصالح }
\end{aligned}
$$

\section{Refrence}

Bessadok, Adel \& Lassaad, Smirani \& Hatem, Khaled \& Almotairi, A. (2018). Internet of Things Users Classification According to Their Technology Readiness Index. International Journal of Internet of Things, 7(2), 37-44 DOI: 10.5923/j.ijit.20180702.03.

Chen, S. C., Liu, M. L., \& Lin, C. P. (2013). Integrating technology readiness into the expectation-confirmation model: an empirical study of mobile services. Cyberpsychology, behavior and social networking, 16(8), 604-612. DOI:10.1089/cyber.2012.0606.

Dasgupta, S., \& Gupta, B. (2010). Organizational Culture and Technology Use in a Developing Country: An Empirical Study. In 16th Americas Conference on Information Systems, AMCIS, (p. 565).

Davis, F. D. (1985). A technology acceptance model for empirically testing new end-user information systems: Theory and results (Doctoral dissertation, Massachusetts Institute of Technology).

Davis, F. D. (1989). Perceived Usefulness, Perceived Ease of Use, and User Acceptance of Information Technology. MIS Quarterly, 13(3), 319-340. DOI: $10.2307 / 249008$.

Davis, F.D., Bagozzi, R.P. and Warshaw, P.R. (1989). User Acceptance of Computer Technology: A Comparison of Two Theoretical Models, Management Science, 35(8), 982-1003.

Demirci, A. E., \& Ersoy, N. F. (2008). Technology readiness for innovative high-tech products: how consumers perceive and adopt new technologies. The Business Review, 11(1), 302-308. 
ECS- Electronic Course System Documentation Manual. (2019). Ministry of Higher Education and Scientific Research, University of Information and Communications Technology, first edition.

Fornell, C., \& Larcker, D. (1981). Evaluating Structural Equation Models with Unobservable Variables and Measurement Error. Journal of Marketing Research, 18(1), 39-50. doi:10.2307/3151312.

Hair, J.F., Hult, G.T.M., Ringle, C.M. and Sarstedt, M. (2017). A Primer on Partial Least Squares Structural Equation Modeling (PLS-SEM). 2nd Edition, Sage Publications Inc., Thousand Oaks, CA.

Lai, Ming-Ling. (2008). Technology Readiness, internet self-efficacy and computing experience of professional accounting students. Campus-Wide Information Systems,25(1);18-29. doi:10.1108/10650740810849061.

Legris, Paul \& Ingham, John \& Collerette, Pierre. (2003). Why do people use information technology? A critical review of the technology acceptance model. Information \& Management, 40(3). 191-204. DOI: 10.1016/S0378-7206(01)00143-4.

Muniasamy, V., Eljailani, I.M., \& Anandhavalli, M. (2014). Prediction of learner perception and acceptance of e-learning system for learning with TAM (Technology Acceptance Model) in King Khalid University, Kingdom of Saudi Arabia. International Journal of Emerging Technology and Advanced Engineering, 4(9), 94-99.

Panday, R., \& Rachmat, B. (2019). Technology Readiness Acceptance Model Analysis on Project Management Operations. International journal of Business Management. 4 (3): 117-132

Parasuraman, A. (2000). Technology Readiness Index (TRI) a multiple-item scale to measure readiness to embrace new technologies. Journal of service research, 2(4), 307-320. doi:10.1177/109467050024001.

Parasuraman, A., \& Colby, C. L. (2015). An Updated and Streamlined Technology Readiness Index: TRI 2.0. Journal of Service Research, 18(1), 59-74. doi:10.1177/1094670514539730.

Pham, L., Nguyen, P. T. H., Huy, L. Van, \& Luse, D. (2018). Technology Readiness and customer satisfaction in luxury hotels: A case study of Vietnam. In International Journal of Entrepreneurship, 22(2), 1-23.

Quintanilla, C., \& Ayala, E. (2011). Employees' Technology Readiness and Service Quality in Mexican Call Centers. Multidisciplinary Business Review, 4(1), 620.

Ringle, Christian M; Wende, Sven; Becker, Jan-Michael. (2015): SmartPLS 3. Bönningstedt: SmartPLS. Retrieved from http://www.smartpls.com.

Thanoon, Alaa. (2016). Practice of Continuous Auditing in accordance with Technology Acceptance Model: An analytical study of a sample of the Iraqi auditing Offices. Journal of Economics and Administrative Sciences, 22(92), 294-314.

Venkatesh, V. \& Davis, F. (1996). A Model of the Antecedents of Perceived Ease of Use: Development and Test. Decision Sciences. 27, 451-481. 